\title{
Critical Review of Electro-kinetic Remediation of Contaminated Soils and Sediments: Mechanisms, Performances and Technologies
}

\author{
Ding Han $\cdot$ Xingyi Wu $\cdot$ Rui Li $\cdot$ Xianqiang Tang • \\ Shangbin Xiao $\cdot$ Miklas Scholz $($ D
}

Received: 1 February 2021 / Accepted: 17 May 2021 / Published online: 10 August 2021

(C) The Author(s) 2021

\begin{abstract}
Remediation of contaminated soil and sediment is important for improving the eco-environmental quality. Electro-kinetic remediation (EKR) is an environmentally friendly technology to migrate and remove pollutants from the soil and sediment matrix. This paper analyses the mechanism and performance of EKR of heavy metals, organic pollutants, and compound pollutants. Moreover, the effect of optimizing individual EKR through soil and sediment pre-treatment (adding acid/oxidant/co-solvent/surfactant, stirring, heating, etc.), electrode optimization (exchange electrode, anode approximation, electrode matrix, etc.), and applying multi-technology combination (electro-kinetic permeable reaction barrier/Fenton/ion, exchange membrane/
\end{abstract}

D. Han $\cdot$ X. Wu $\cdot$ S. Xiao

College of Hydraulic \& Environmental Department, China Three Gorges University, Yichang 443002, China

\section{Han $\cdot$ X. Wu $\cdot$ R. Li $\cdot$ X. Tang}

Basin Water Environment Department, Changjiang River Scientific Research Institute, Wuhan 430010, China

R. Li $\cdot$ X. Tang $(\bowtie)$

Key Lab of Basin Water Resource and Eco-environmental Science in Hubei Province Changjiang River Scientific Research Institute, Wuhan 430010, China

e-mail: ckyshj@126.com

\section{Scholz $(\bowtie)$}

Division of Water Resources Engineering, Faculty of Engineering, Lund University, P.O. Box 118, 22100 Lund, Sweden

e-mail: miklas.scholz@tvrl.lth.se ultrasonic/electrolyte enhancement, etc.) was evaluated. Factors including incomplete separation of pollutants, variation in physico-chemical properties and microstructure of soil/sediment, and difficulties in in situ practice have restrained the field application of EKR. To solve the above technical challenge, an integrated EKR technology based on pollutant in situ separation, followed by separated contaminant treatment, and subsequent valuable elements recovery is proposed.

Keywords Soil pollution - Electro-kinetic remediation Enhanced method $\cdot$ Pore water $\cdot$ Electrode $\cdot$ In situ separation

\section{Scholz}

Department of Civil Engineering Science, School of Civil Engineering and the Built Environment, University of Johannesburg, Kingsway Campus, PO Box 524, Aukland Park, Johannesburg 2006, South Africa

\author{
M. Scholz \\ Department of Town Planning, Engineering Networks and \\ Systems, South Ural State University (National Research \\ University), 76, Lenin prospekt, Chelyabinsk 454080, Russian \\ Federation \\ M. Scholz \\ Institute of Environmental Engineering, Wroclaw University of \\ Environmental and Life Sciences, ul. Norwida 25, \\ 50-375 Wrocław, Poland
}




\section{Soil and Sediment Treatment by Electro-kinetic Remediation}

Mining, electroplating, and other industrial activities, as well as sewage irrigation, the use of chemical fertilizers, and other agricultural production processes, lead to large amounts of heavy metals and organic pollutants accumulating in the soil and/or sediment. These pollutants can bio-accumulate in living organisms and cause a threat to the health of plants and animals including humans (Forstner, 2004; Li et al., 2018).

Soil and sediment pollution has become a global environmental crisis. A variety of remediation technologies have been developed for soil and sediment pollution, including solidification-stabilization, phytoremediation, and leaching. However, these methods have certain limitations in their application scope. For example, in bioremediation, the mobility of microorganisms in soil is poor. Organisms are easily inhibited by the toxic effect of pollutants. In phytoremediation, the absorption and accumulation of pollutants by hyperaccumulators are very slow, and the remediation time is often too long for practical purposes. Leaching requires higher soil permeability, and the legacy of a leaching agent may cause secondary pollution. In addition, in the process of remediation, due to the comprehensive influence of different pollutant properties and soil characteristics, it is difficult for the aforementioned remediation technology to quickly and effectively remediate contaminated soil with low permeability. In such a case, electric remediation technology has received more attention.

EKR is a technology for migration, separation, and removal of pollutants in soil and sediment under an electric field, which is cost-efficient and has low environmental impacts (Vocciante et al., 2017). Casagrande (1948) firstly tested the principle of electroosmosis on real soil in the field, and consolidated soft clays by employing an electric current. In the early days, the technology was mainly used for sediment dehydration as well as strengthening of foundations (Micic et al., 2001). During the late 1980s, directional migration of ions in the electric field was first discovered within the process of electric dehydration, and the application of the EKR concept to remove heavy metals from contaminated soil was proposed in 1992 (Lindgren et al., 1994). Subsequent experiments have, for example, confirmed that between 85 and $95 \%$ of phenol can be removed from saturated kaolin when EKR is applied (Acar et al.,
1992). Over the last few decades, EKR has been widely used in the removal of a variety of pollutants including heavy metals such as $\mathrm{Cu}, \mathrm{Pb}, \mathrm{Zn}$, and $\mathrm{Cd}$ (Al-Hamdan \& Reddy, 2008; Ferro et al., 2014); organic pollutants including phenanthrene, thorium, triclosan, aniline, and phenol (Chung \& Kamon, 2005; Li et al., 2000; Ricart et al., 2008); salts such as fluorine, nitrate, and phosphorus (Kim et al., 2012; Lee et al., 2011; Tang et al., 2020; Zhou et al., 2014; Zhu et al., 2009); and radioactive substances such as uranium (Mao \& Pan, 2015; Xiao et al., 2020).

Using two or more remediation methods at the same time to form a joint remediation system can not only improve the remediation rate and efficiency of single contaminated soil, but also overcome the limitations of single remediation technologies. Permeable reaction walls, electric Fenton, phytoremediation, and ultrasound (Cang et al., 2011; Fernández de Dios et al., 2014; Mumford et al., 2015; O'Connor et al., 2003; Pham et al., 2009) have been integrated into EKR technology.

At present, laboratory work progress linked to EKR technology has been considerable, but it still has great difficulties to overcome in engineering practice. There are still some technical problems to be solved, among which the most important challenges include $\mathrm{pH}$ control at both sides of the electrode, the "polarization effect," and the "focusing effect" (to be described in more detail in the second part).

\section{Mechanisms and Models to Understand Electro-kinetic Remediation}

\subsection{Mechanisms}

EKR achieves the purpose of remediation by applying an electric field to the contaminated soil/sediment, enriching the pollutants to the cathode or anode zone through electroosmosis, electromigration, and electrophoresis (Fig. 1). Electric migration is the movement of charged dissolved ions through an aqueous medium toward the electrode with a polarity opposite the ion charge (Wang et al., 2021). Electro-osmosis is the movement of pore fluid and dissolved constituents within a porous medium that typically occurs between the anode and cathode, because of the negative charge characteristic of the soil particle surface (Cameselle \& Reddy, 2013). However, the change of surface charge of soil may change the direction of electroosmosis. 


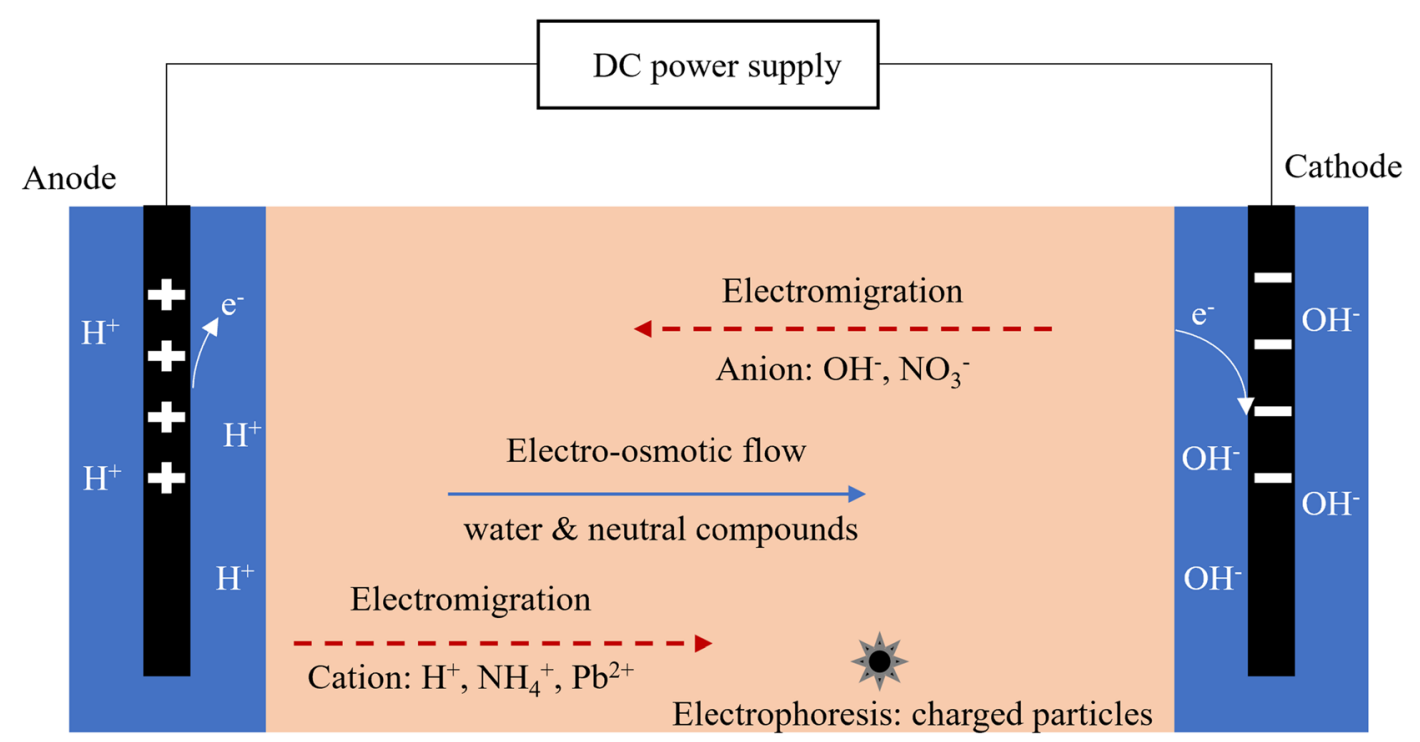

Fig. 1 Schematic diagram of (a) the electro-kinetic remediation principle (DC, direct current); and (b) comparison of electroosmotic flow in a single capillary

Electrophoresis refers to the transport of charged particles or colloids in soil under the action of an electric field. Soil organic matter, microbial cells, and small soil particles are colloids, and when heavy metals and other pollutants are adsorbed on the surface of colloid or charged particles, they will be discharged together. However, the effect of electrophoresis can be ignored, because of the low mobility of charged soil particles in the process of electric remediation. Therefore, the actual migration speed of heavy metal ions in soil pore water is determined by the action of electric migration and electroosmosis under the action of an external direct current electric field.

In the electro-kinetic remediation process, the liquid phase mass transfer of pollutants is mainly realized through four processes: electromigration, electroosmotic flow, convection, and diffusion (Acar et al., 1993). For EKR, electroosmosis and electromigration contribute most to the pollutant removal, while electrophoresis and electrochemical oxidation occurs only for some types of pollutants (Table 1). The most possible reason for this is that within the process of compacting the soil/sediment matrix, free movement of large colloidal particles is usually limited, while the dissolved pollutants in pore water migrate relatively easily (Reddy \& Saichek, 2003). The migration rate and amount of ions are related to the porosity, ion charge, soil temperature, soil moisture, and voltage potential (Acar \& Alshawabkeh, 1993).

Organic pollutants are electrically neutral in general, and the main mechanism for electrically removing organic pollutants from soil and sediment is

Table 1 Characteristics for electro-kinetic remediation treating different kinds of pollutants

\begin{tabular}{lllll}
\hline Target pollutants & & Pollutant properties & Dominant removal processes \\
\hline Heavy metals & $\mathrm{Cd}, \mathrm{Pb}$, and $\mathrm{Hg}$ & $\begin{array}{c}\text { Easily to form a precipitate with } \mathrm{OH}^{-} \\
\text {and low solubility }\end{array}$ & Electromigration and electroosmosis \\
\hline Organic pollutants & $\begin{array}{c}\text { PCB, PAH, and petroleum } \\
\text { hydrocarbons }\end{array}$ & $\begin{array}{c}\text { Low solubility, difficult to biodegrade, } \\
\text { adsorbs to sediment particles and } \\
\text { electrically neutral }\end{array}$ & $\begin{array}{c}\text { Electroosmosis, electromigration } \\
\text { (charged), and electrochemical } \\
\text { oxidation }\end{array}$ \\
Inorganic ions & $\begin{array}{c}\text { Nitrite, fluorine, radioactive } \\
\text { species (Ur and Cs) } \\
\text { Mixed pollutants }\end{array}$ & $\begin{array}{c}\text { High solubility } \\
\text { pollutants }\end{array}$ & Active interaction between pollutants & Electromigration and electroosmosis \\
& & & Electromigration and electroosmosis
\end{tabular}


electroosmosis (Alcántara et al., 2010). Acar et al. (1992) and Bruell et al. (1992) carried out experiments to remove phenol and hydrocarbons (benzene, toluene, and trichloroethylene) from kaolin and clay. They found that EKR can remove a certain amount of organic pollutants from fine soil particles by electroosmosis. However, the application of an electric field does not promote the dissolution and desorption of organic matter. For inorganic nutrients such as nitrate, electromigration dominates the removal process, and EKR can remove $90 \%$ of nitrate, and the residual nitrate ions in the soil are mainly concentrated near the anode (Manokararajah \& Ranjan, 2005; Zhou et al., 2015).

For mixed pollutants, the interactions between different pollutants may occur when EKR is applied. EKR was performed with mixed azo dye-and Cr-contaminated soil. It was found that interaction between $\mathrm{Cr}$ and azo dye prevented the premature precipitation into the soil matrix and enhanced the removal rate of organic pollutants and heavy metals (Ricart et al., 2008). When EKR is applied to textile wastewatercontaminated soil, the removal of inorganic salts and metal ions conforms to the characteristic of electromigration and electroosmosis, but the $\mathrm{Cu}^{2+}$ anomaly migrates to the anode zone. It is implied that $\mathrm{Cu}^{2+}$ and organic groups recombine and migrate to the anode with the organic groups during the EKR process (Annamalai et al., 2014).

Soil and sediment physico-chemical characteristics near the electrodes will be greatly impacted on by electrolysis reactions at the early stages of the EKR. The electrolytic reactions are shown in Eqs. (1) and (2):

Anode : $2 \mathrm{H}_{2} \mathrm{O}-4 \mathrm{e}^{-} \rightarrow \mathrm{O}_{2} \uparrow+4 \mathrm{H}^{+} ; \mathrm{E}_{0}=-1.229 \mathrm{~V}$

Cathode : $2 \mathrm{H}_{2} \mathrm{O}+4 \mathrm{e}^{-} \rightarrow \mathrm{H}_{2} \uparrow+2 \mathrm{OH}^{-} ; \mathrm{E}_{0}=-0.828 \mathrm{~V}$

where $\mathrm{E}_{0}$ is the standard reduction potential.

At the anode, water loses electrons, generating $\mathrm{H}^{+}$ and $\mathrm{O}_{2}$, and the created $\mathrm{H}^{+}$ions move to the cathode electrolysis cell under the electric field, which can make the heavy metals in the soil dissolve into the pore water and improve the movement rate (often also the removal rate) of heavy metals, but excessive numbers of $\mathrm{H}^{+}$ions at the anode are easy to lead to soil acidification, corrosion of anode materials, and even a change in the direction of the electro-osmosis flows (Wang et al., 2021).
At the cathode, water is reduced leading to the production of hydrogen gas and hydroxide ions, generating $\mathrm{OH}^{-}$and $\mathrm{H}_{2}$ ions. The generated $\mathrm{OH}^{-}$ions move to the anode under the action of the electric field. In the process of $\mathrm{OH}^{-}$migration, heavy metal ions may precipitate before reaching the cathode (namely the focusing effect), which reduces the movement rate of heavy metals and hinders the removal of heavy metals in soil ( $\mathrm{Wu}$ et al., 2021).

There are three situations that will lead to the relative increase of voltage near the electrode (namely the polarization effect) and affect the efficiency of EKR: (1) the concentration polarization caused by the concentration difference between the solution near the electrode and the bulk solution; (2) the resistance polarization caused by a layer of insoluble insulating salt or other insoluble impurities on the cathode surface inhibits the soil conductivity and decreases the current density; and (3) the activated polarization caused by the bubbles (composed of $\mathrm{H}_{2}$ and $\mathrm{O}_{2}$ or other gases) on the electrode surface. When they cover the respective electrode surface, the conductivity between the electrode and the electrolyte will be reduced. The polarization effect will hinder the migration of ions and affect the speed of electrodialysis (Lucas et al., 2019; Rojo et al., 2012).

In addition, soil heterogeneity and voltage gradient are key factors affecting the EKR. Soil mineral composition and buffering capacity affect the pollutant transportation rate. Saturated water content and low ionic strength of soil are the most favorable conditions for electroosmosis and pollutant migration. When the soil plasticity value exceeds 35 , the soil will shrink excessively during the remediation process, leading to soil cracking and disturbing the pollutant removal mechanism (López-Vizcaíno et al. 2016a, b). The range of voltage gradient used in laboratory tests is $1-3 \mathrm{~V} / \mathrm{cm}$ (Li et al., 2018; Zhu et al., 2009). The high current level can increase the total ion concentration and improve the ion electromigration efficiency in the electro-kinetic remediation process (Tang et al., 2020), but it will reduce the overall electroosmotic flow and release a lot of heat (Joule effect), resulting in energy consumption and relatively high costs (Xue et al., 2017).

\subsection{Models}

Numerical models can be useful tools to further understand and predict the processes that influence the efficiency of EKR and to precisely design, optimize, and 
control EKR systems (Sprocati et al., 2019). When dealing with extremely complicated and challenging variables, modeling before starting an operation can significantly reduce the time and cost of such a process by allowing an accurate prediction of possible outcomes.

Cabrera-Guzmán et al. (1990), Acar et al. (1993), and Probstein and Hicks (1993) assimilated the traditional electrochemical, soil colloid dual-mode and mass transfer theories, and established a preliminary thermodynamic model to describe conduction phenomena under electrical and hydraulic potentials. In the presence of hydraulic, electrical, and chemical gradients, the one-dimensional total flux of species $j$ per unit area of the soil medium is given by Acar and Alshawabkeh (1993) in Eq. (3):

$J_{j}=-D_{j}^{*} \frac{\partial C_{j}}{\partial x}-C_{j}\left(u_{j}^{*}+k_{e}\right) \frac{\partial E}{\partial x}-C_{j} k_{h} \frac{\partial h}{\partial x}$

where $J_{j}$ is the total flux of species $j, D^{*}$ is the effective diffusion coefficient of species $j, C_{j}$ is the concentration of species $j, u^{*}$ is the effective ionic mobility, $E$ is the electric potential difference, $k_{e}$ is the electroosmotic coefficient of permeability, $h$ is the hydraulic head, $k_{h}$ is the hydraulic conductivity of the soil, and $x$ is the linear distance.

The theoretical and experimental results showed that the electrical potential difference profile across the specimen is non-linear. The efficiency of removal of a specific species will decrease in time as its concentration with respect to other species in the pore fluid decreases (Acar \& Alshawabkeh, 1993). Although the early electric remediation models can estimate the total mass flux of contaminants, and simulate the acid-base distribution in the system as well as analyze the relative contribution of electroosmosis and electromigration (Acar et al., 1993), these models are based on the assumption of homogeneous porous media, and most of them adopt indoor simulation such as kaolin. Therefore, there are still some limitations for the applications of electro-kinetic models to large-scale experiments.

Models of electro-kinetic soil remediation systems have been developed significantly in recent decades (Table 2). In 2002, an electromigration transport model for ion transport in unsaturated soil was developed by Mattson et al. (2002a). The numerical model was based on the groundwater flow and transport codes MODFLOW and MT3D, which have been modified to account for electrically induced ion transport.
Most past studies were concerned with determining the residual contaminant distribution in the soil and measuring the overall removal efficiency after the electro-kinetic treatment. Al-Hamdan and Reddy (2008) developed the computer model EKGEOCHEM (ELECTROKINETIC GEOCHEMICAL) to calculate the concentration of any chemical species during electro-kinetic remediation as a function of time and space. It is generally accepted that the most consistent theoretical model for macroscopic EKR processes consists of the combination of mass balance equations coupled with the electro-neutrality condition, where the main transport mechanisms are electro-migration for charged species and electro-osmosis for neutral (non-charged) species (Jacobs \& Probstein, 1996; Rodríguez-Maroto \& Vereda-Alonso, 2009).

Few studies have been conducted with models that simulate the transport of heavy metals by including the process of switching electrodes, because of the complexity involved with the changes in the initial conditions. Sun et al. (2019) established a piecewise model to simulate the transport of $\mathrm{Cd}$ under a superimposed electric field. This research indicated progressive soil acidification; the "focusing" region of $\mathrm{Cd}$ was compressed by the migration of the acid front. The removal efficiency can be optimized by modeling and switching electrodes.

The most advanced simulators typically include the coupling of the physical mass transfer processes with geochemical databases to simulate EKR in saturated porous media (Sprocati et al., 2019). Sprocati et al. (2019) propose a multi-dimensional modeling approach that allows for the integrated description of fluid flow, solute transport (including electromigration and electroosmosis), coulombic interactions between transported species, and a wide range of kinetic and equilibrium reactions. The proposed modeling tool NP-Phreeqc-EK is a coupling between COMSOL Multiphysics, which is applied to solve fluid flow and solute transport challenges in saturated porous media based on the Nernst-Planck-Poisson formulation, and PhreeqcRM, which is used to solve geochemical reactions. López-Vizcaíno et al. (2017) proposes a conceptual and numerical model that includes geochemical speciation other than the phenomena that have been described by other studies. The results show that the buffering system of carbonates affects the temporal evolution and spatial distribution of $\mathrm{pH}$. They emphasize that simulations using realistic geochemical systems are critical. 


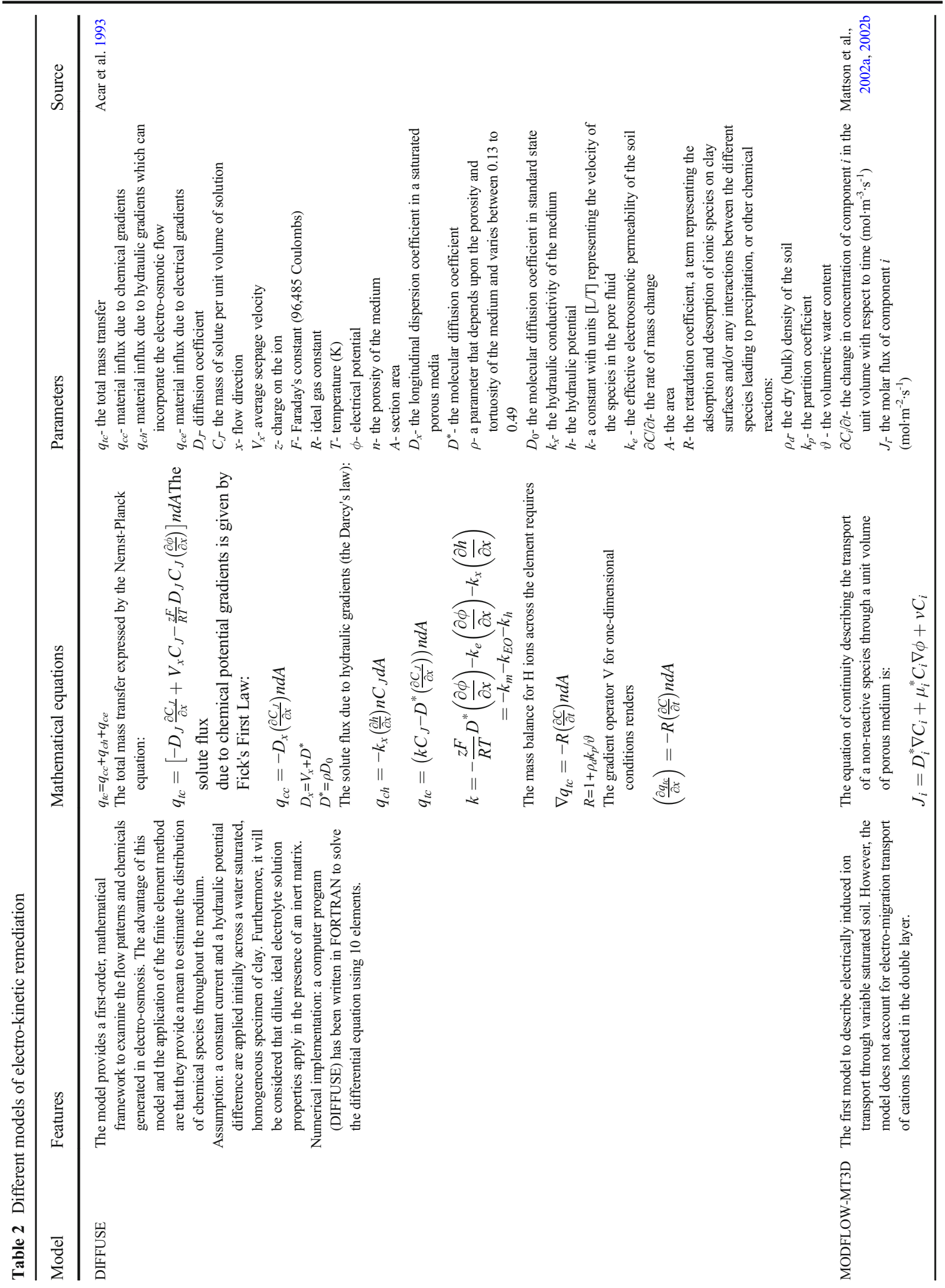




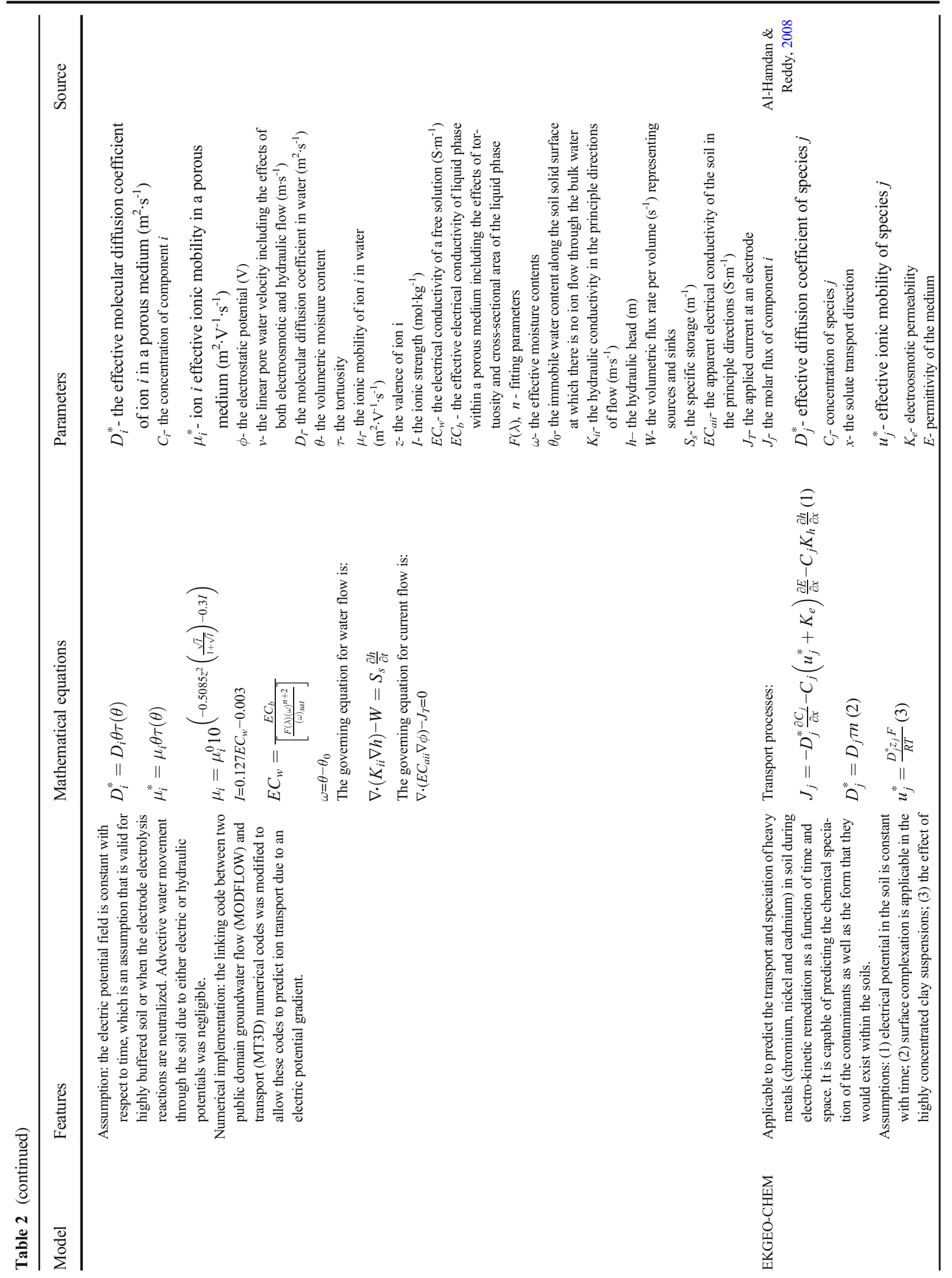




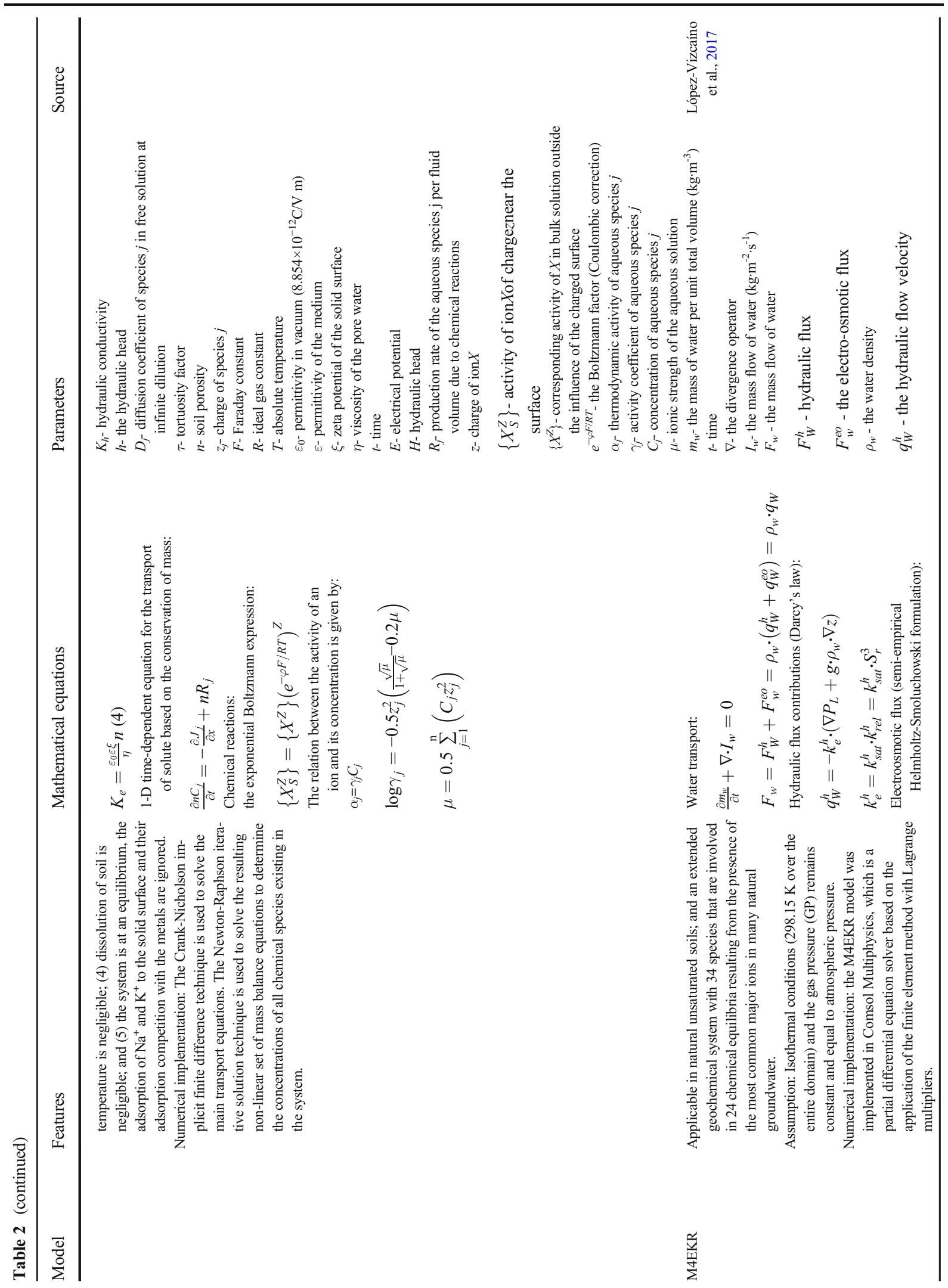




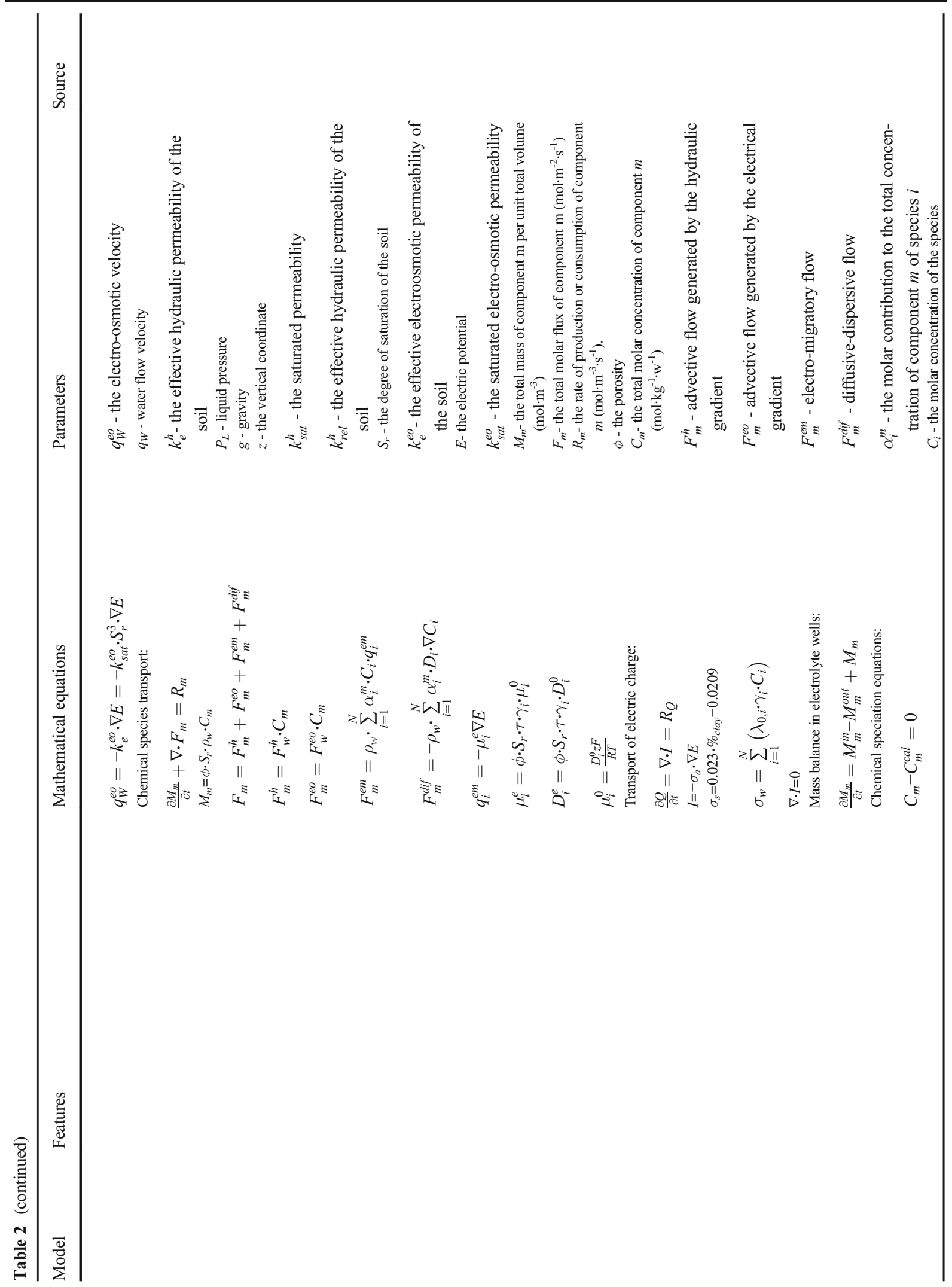




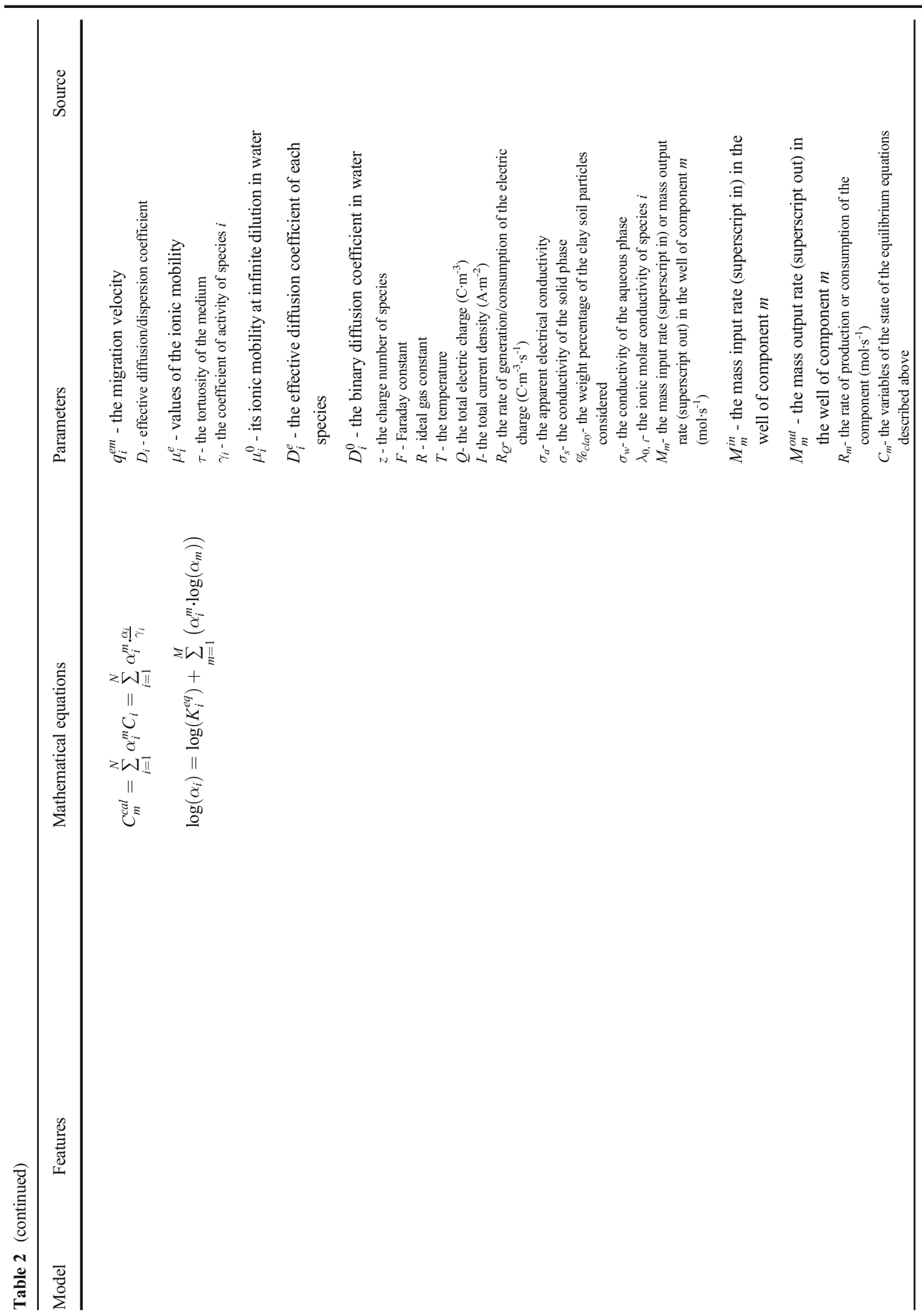




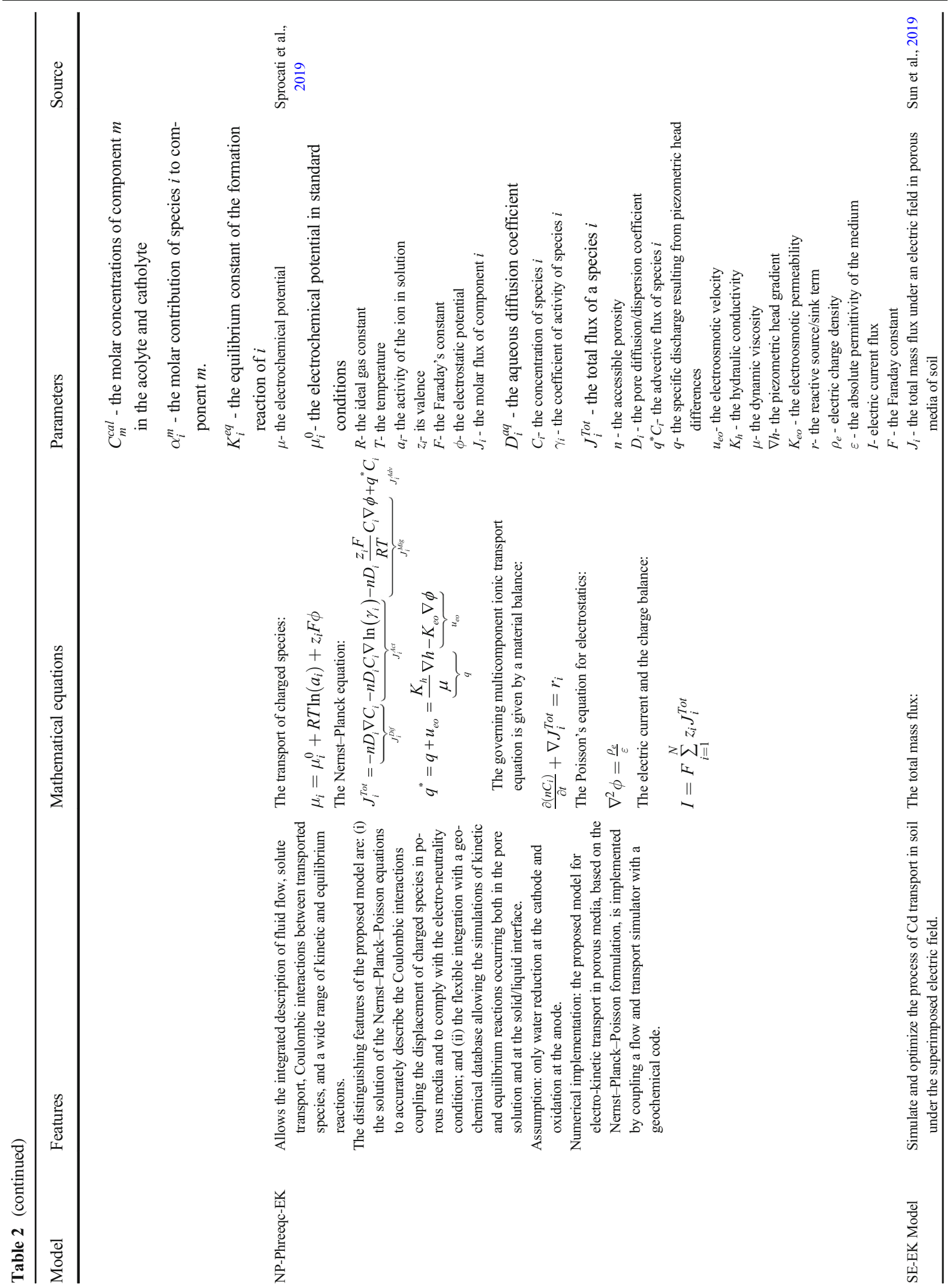




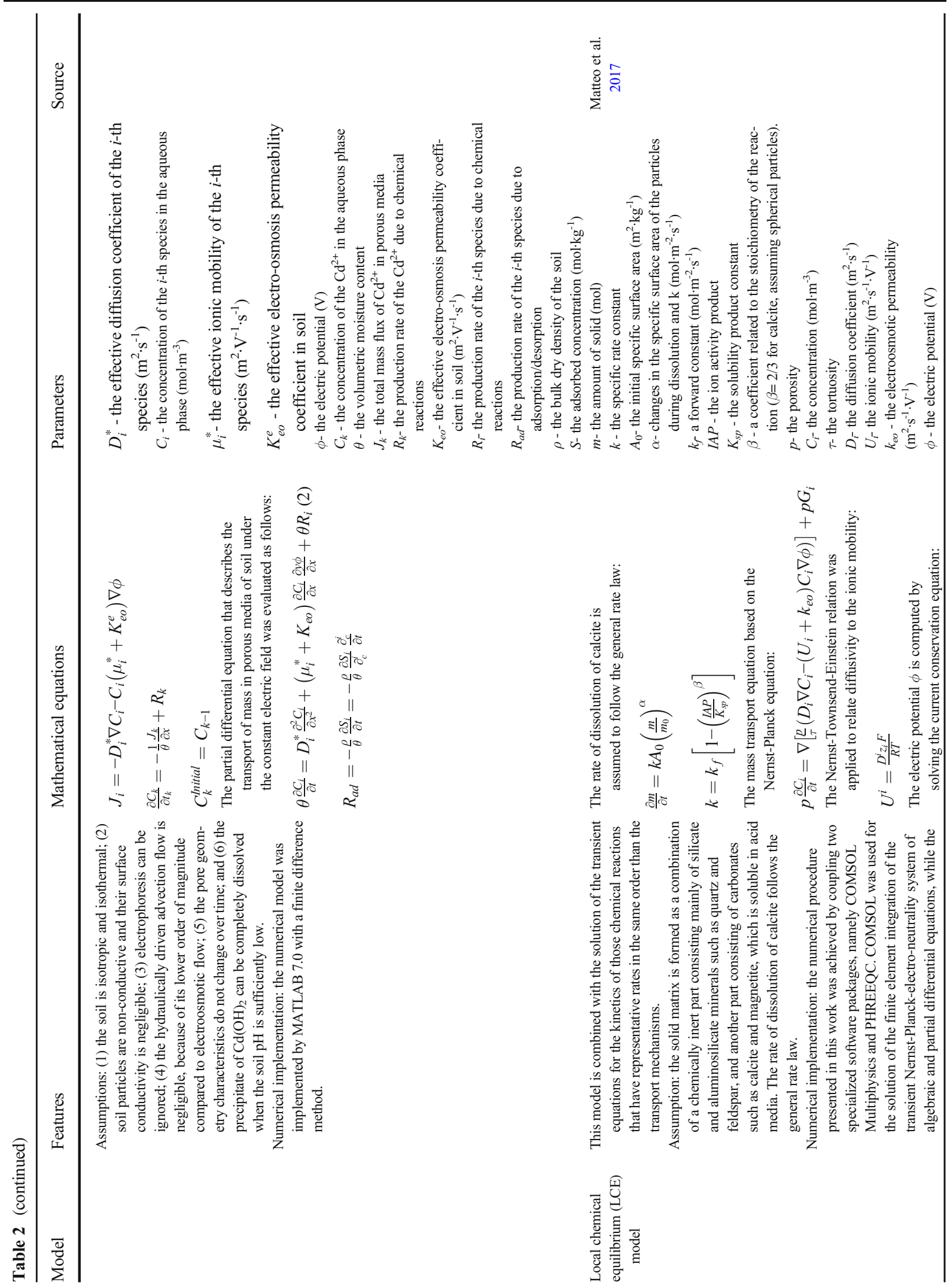




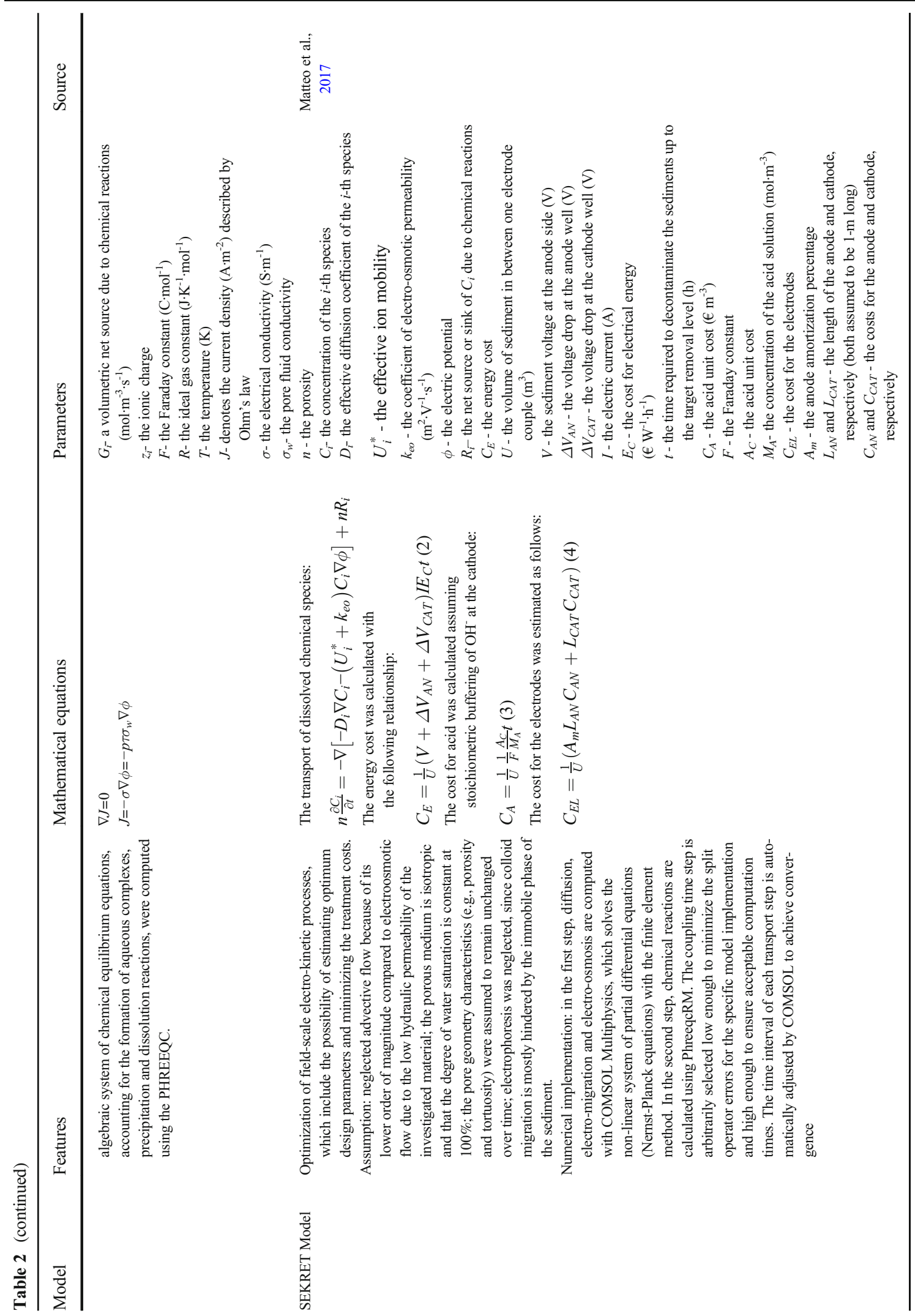


In many cases, laboratory experiments can be excessively time-consuming, and modeling could become a necessary tool to assess the main remediation parameters and predict achievable results. Despite electro-kinetic applications have shown promising results, quantitative understanding of such systems is still challenging due to the complex interplay between physical transport processes, electrostatic interactions, and geochemical reactions in multiple dimensions (Sprocati $\&$ Rolle, 2020). To find the optimum set of design parameters for cost minimization is also a development trend of current research.

\section{Technical Approaches to Improve Electro-kinetic Remediation Performances}

The efficiency of EKR depends mainly on the activation such as desorption and dissolution of contaminants as well as migration of pollutants. However, some pollutants such as $\mathrm{Hg}, \mathrm{Cd}$, and $\mathrm{HOC}$ are relatively insoluble, and it is difficult to achieve adequate activation and migration with a single EKR. In addition, the $\mathrm{pH}$ value, the polarization of electrodes, and pollutant accumulation also affects the efficiency of EKR (Altin \& Degirmenci, 2005; Isosaari et al., 2007). When a single EKR is conducted, heavy metal removal rates usually range between 14 and $59 \%$, and the removal rate of organic pollutants ranges even between 9 and $61 \%$ (Table 3). Moreover, there are significant differences in the removal efficiency of different pollutants even if the same EKR technology is applied. In general, a single EKR is suitably used to optimize the mechanistic parameters for target pollutants in given contaminated soil and sediment. In order to enhance the mobility and removal rate of pollutants, and reduce the side effects, many techniques including separation and reaction of pollutants, electrolyte $\mathrm{pH}$ adjustment, electrode optimization, and multi-technology combination have been developed to improve EKR performance (Fig. 2).

\subsection{Separation and Reaction of Pollutants}

Organic complexing agents can react with difficult-to-dissolve heavy metals to form soluble complexes, which will improve the migration efficiency of heavy metals. $\mathrm{NaClO}$ can also be used as an oxidant for a catholyte (Cang et al., 2007). The efficiency of metal extraction through electro-kinetics was the highest when both the anodic and the cathodic chambers were conditioned with the complexing agent ethylenediaminetetraacetic acid. The following removal yields were obtained: $81 \%$ for $\mathrm{As}, 69 \%$ for $\mathrm{Cr}, 40 \%$ for $\mathrm{Cu}, 33 \%$ for $\mathrm{Pb}$, and $22 \%$ for $\mathrm{Zn}$ (Andreottola et al., 2010). Adding potassium permanganate oxidant to the catholyte increased the removal rate of $\mathrm{Cr}$ from 32 to $78 \%$.

Furthermore, López-Vizcaíno et al. (2018) presents an EKR study of soils polluted with 2,4-dichlorophenoxyacetic acid (a common polar pesticide), enhanced with an anolyte $\mathrm{pH}$ conditioning strategy. By using $0.1 \mathrm{~mol} / \mathrm{L} \mathrm{NaOH}$ as the anolyte, the removal rate of fluorine reached $70 \%$. Moreover, applying $\mathrm{NaOH}$ not only enhances the remediation of fluorine-contaminated soil, but also enhances the removal potential of other anionic pollutants such as arsenate and chromate (Zhou et al., 2015).

An oxidant can change the solubility and degradation rate of pollutants. For example, mercury exists in natural soil in the form of $\mathrm{HgS}, \mathrm{Hg}$, and $\mathrm{HgO}$. All of them have very low solubility, which results in the challenge of EKR to address Hg-contaminated soil challenges. In 1996, Cox et al. (1996) demonstrated the potential of iodine/iodide lixiviant for maintaining proper thermodynamic conditions for effective electro-kinetic remediation of $\mathrm{Hg}$-contaminated soils, and more than $90 \%$ of $\mathrm{Hg}$ existed in the form of $\mathrm{HgI}_{4}{ }^{2-}$. The ultimate removal rate of $\mathrm{Hg}$ in contaminated soil reached $99 \%$.

Adding a co-solvent can effectively increase the solubility of certain organic matter in the soil and reduce the adsorption of hydrophobic organic pollutants so that more organic matter can be removed from the contaminated soil by electroosmosis. A series of bench-scale electro-kinetic experiments indicated that phenanthrene was migrating toward the cathode in proportion to the concentration of n-butylamine. The extent of migration was dependent on the n-butylamine concentration and the strength of electroosmotic flow (Maturi \& Reddy, 2008).

Adding surfactants to the contaminated soil can reduce the activation energy on the soil particles, which will achieve the purpose of removing pollutants by promoting desorption of pollutants. The non-ionic surfactant Tween 80 (Polysorbate 80) and the anionic surfactant sodium dodecyl sulfate (SDS) were used to aid desorption of PAH from the soil, and the removal rate of $\mathrm{PAH}$ reached a maximum of almost $87 \%$ (Lima et al., 2012). Tween 80 , polyoxyethylene ether, modified cyclodextrin, 
Table 3 Pollutant removal via electro-kinetic remediation with different soil properties

\begin{tabular}{|c|c|c|c|c|c|}
\hline \multirow[t]{2}{*}{ Pollutants } & \multicolumn{3}{|c|}{ Soil property } & \multirow[t]{2}{*}{ Removal rate } & \multirow[t]{2}{*}{ Sources } \\
\hline & Type & Moisture content $(\%)$ & $\mathrm{pH}$ & & \\
\hline $\mathrm{Cr}$ & Artificial & 13.5 & 7.48 & $59.0 \%$ & Lu et al. 2009 \\
\hline $\mathrm{Cr}(\mathrm{III})$ & Natural & 30 & l & $20.9 \%$ & Meng et al., 2018 \\
\hline $\mathrm{Cr}(\mathrm{VI})$ & Artificial & l & 3.76 & $37.6 \%$ & Almeira et al., 2012 \\
\hline $\mathrm{Pb}$ & Artificial & $50-54$ & $4.93-5.20$ & $22.3 \%$ & Kim et al., 2005 \\
\hline $\mathrm{Pb}$ & Artificial & 37.55 & 5.7 & $52.9 \%$ & Li et al. 2005 \\
\hline $\mathrm{Cd}$ & Artificial & $50-54$ & $4.93-5.2$ & $14.2 \%$ & Kim et al., 2005 \\
\hline$\alpha-\mathrm{HCH}$ & Natural & l & 6.28 & $60.9 \%$ & Ni et al., 2018 \\
\hline $\mathrm{P}$ and P-DDT & Natural & l & 6.28 & $40.0 \%$ & Ni et al., 2018 \\
\hline Phenanthrene & Artificial & I & l & $9.4 \%$ & Sun et al., 2017 \\
\hline Trichlorophenol & Artificial & / & 1 & $14.3 \%$ & Sun et al., 2017 \\
\hline
\end{tabular}

and N-butyl amine are often used as the surfactants to improve EKR performance (Sun et al., 2017). The requirements of selecting complexing agents are that (a) the ligands should have high solubility in solutions with a wide $\mathrm{pH}$ range; (b) formers are not easy to adsorb on the soil surface; and (c) formers should be non-toxic or have low toxicity with little potential risk to the environment.

Heating and stirring are considered as physical pre-treatment methods in this sub-chapter.

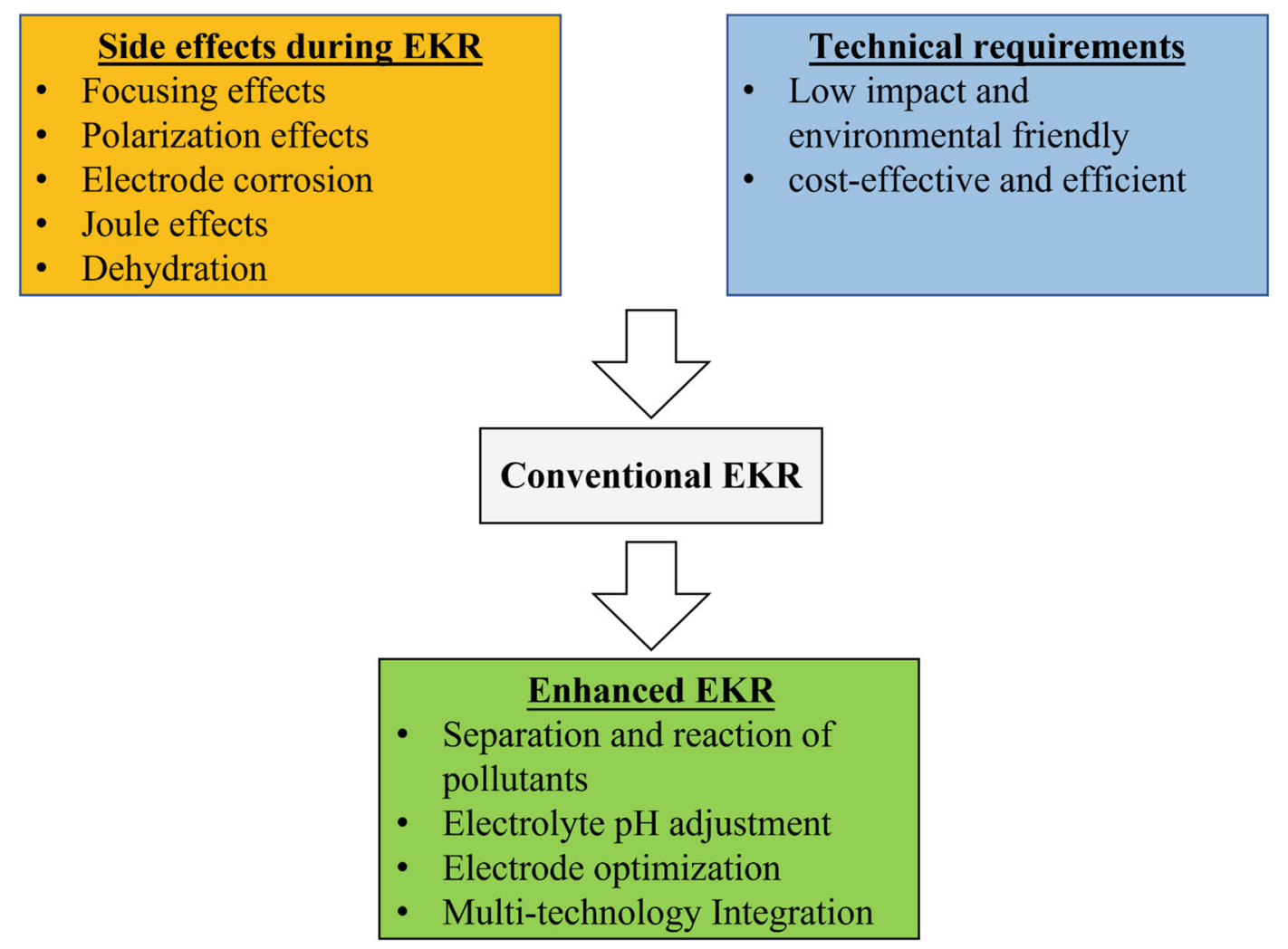

Fig. 2 Schematic diagram of the enhanced electro-kinetic remediation technology 
Temperature mainly influences the ionic migration velocities, and can promote electromigration and electroosmosis as it increases. Increasing the soil and sediment temperature can accelerate the migration and diffusion of pollutants, which applies to ectopic EKR (Baraud et al., 1999). Elevating the soil temperature from 21 to $55^{\circ} \mathrm{C}$ reduced the time to extract potassium dichromate from kaolinite soils under saturated conditions. Conversely, increasing the soil temperature under dewatering conditions caused soil cracking, which reduces the overall process efficiency (Krause \& Tarman, 1993).

Stirring is an alternative effective way to speed up the process of removing pollutants. It helps to enhance soil aeration and mixing, while increasing the bioavailability of pollutants. A stirred soil setup was applied when removing pollutants from heavily oil-contaminated soil with EKR, which led to removal efficiencies of up to $70 \%$ for total hydrocarbons and $65 \%$ for polyaromatic hydrocarbons (Pedersen et al., 2016). A combination of adding a surfactant and stirring was successfully used in the field of soil remediation to increase the removal efficiency of PAH by $79 \%$ (Lima et al., 2012).

\subsection{Electrolyte $\mathrm{pH}$ Adjustment}

Protons produced from the oxidation of organics at an anode result in anolyte acidification. Adding non-buffered saline catholyte effluent (e.g., from a previous cycle) to the anolyte leads to the mitigation of anolyte acidification (Davis et al., 2013). In addition, nitric acid can also induce the $\mathrm{pH}$ variations of the catholyte. For example, $0.06 \mathrm{M}$ nitric acid has successfully been used to extract $98 \%$ of $\mathrm{Cd}$ from kaolin (Almeira et al., 2012). Adjusting the $\mathrm{pH}$ of contaminated soil can enhance the activity and the migration ability of pollutants during the electro-kinetic process, and thus increase the removal efficiency of the pollutants. Heavy metals are mainly present in the form of fractions of the following nature: exchangeable, carbonate-bound, $\mathrm{Fe}-$ Mn oxide bound, organic matter, and residual. Before EKR is performed, engineers have to add acids (acetic, lactic, humic, citric, ascorbic, and polyaspartic) to the soil to increase the concentration of dissolved heavy metals, and subsequently enhance the removal rate of heavy metals in soil by 15 to 59\% (Fu et al., 2017; Zhou et al., 2004). Someone could also dissociate some organic matter into anions to accelerate the EKR process.
For example, by adjusting the soil $\mathrm{pH}$ to 9.3 with $\mathrm{NaOH}$ dissociated phenol and 2,4-DCP to obtain phenate anions, the mobility of phenol and 2,4-DCP can be increased by 2 and 5 times, respectively (Luo et al., 2005).

Inserting a cation exchange membrane and an auxiliary solution cell between the cathode and the soil has been proposed, which could make hydroxide ions generated by the electrolysis of water to be isolated within an auxiliary solution cell to prevent metal precipitation in the region near the cathode. This method was successfully used to treat $\mathrm{Pb}$ and $\mathrm{Cd}$ from artificially contaminated kaolin. Researchers observed an increase in the removal rates of $\mathrm{Pb}$ and $\mathrm{Cd}$ from $22 \%$ and $14 \%$ to $92 \%$ and $58 \%$, respectively (Kim et al., 2005).

\subsection{Electrode Optimization}

This sub-chapter addressed the electrode optimization techniques' polarity exchange and approaching anodes. Methods to optimize electrode material, change the electrode structure and shape, and configure electrodes differently and pulse-power electrodes are also considered.

Polarity exchange could avoid the negative effect of $\mathrm{OH}^{-}$on metal transportation, which makes the generation of $\mathrm{H}^{+}$ions from the oxidation of water neutralize the alkaline zone where the metal is precipitated, favoring its dissolution. The application of the polarity exchange method increased Mn removal from 14 to $72 \%$ in 7.6 days (Pazos et al., 2006). Applying electric fields always cause a dramatic change in soil microbial community structure. However, polarity exchange could effectively reduce negative effects on microbial communities (Kim et al., 2010).

The approaching anode electro-kinetic (AA-EK) method, which involves sequentially moving the anodic electrode approach to the fixed cathode, promotes the production of $\mathrm{H}^{+}$, and increases the dissolution and removal of heavy metals and other pollutants, thus maintaining more mobile ions in the system and avoiding the "focus" effect (Shen et al., 2007; Tang et al., 2021). During the electro-kinetic process of approaching anodes, the energy utilization efficiency is increased, the migration and removal rates of $\mathrm{Cd}$ in soil can be increased by more than 1.5 times than the rates of conventional methods, and the remediation time is reduced by $40 \%$ (Shen et al., 2007).

Electrolysis reactions in the vicinity of electrodes may change the solubility and speciation of 
contaminants (Zhou et al., 2004). Acidic conditions and electrolytic decay can corrode some anode materials (Davis et al., 2013); thus, the effect of electrode materials on the efficiency of electric repair should not be ignored. There are two types of optimizing electrode materials: changing the material of the electrode itself or coating active materials to the electrode surface layer. $\mathrm{Ti} \mid \mathrm{IrO}_{2}-\mathrm{Ta}_{2} \mathrm{O}_{5}$ was demonstrated as the best anode material in an EKR process, which showed the highest current density and corrosion-resistance (Méndez et al., 2012).

Changing the electrode structure can allow the pore water near the cathode to be drained fast and avoid the accumulation of hydroxyl, which greatly reduces the combination of heavy metals and hydroxyl to prevent the formation of deposits. An electro-kinetic geosynthetics electrode with flumes transformed from graphite electrodes can be used in experiments to remove $\mathrm{Cd}$ from paddy soil. The use of the EKG electrode avoided the corrosion of the anode and the formation of the precipitation of heavy metals near the cathode, which makes the separation rate of $\mathrm{Cd}$ in the paddy soil reach almost $42 \%$ (Tang et al., 2017).

The shape of the electrode also determines the strength and distribution of the electric field, which affects the migration rate of a pollutant. Using a ring electrode can more conveniently discharge pollutants compared with the use of a rectangular electrode structure. Moreover, under the same voltage gradient, the columnar electrode can produce a non-uniform electric field to greatly increase the electric field intensity in the center area compared to the plate electrode, which will improve the efficiency of the enrichment of organic pollutants at the cathode. After remediation, organic pollutant content in the center of the soil near the cathode can increase by between 98 and 124\% (Luo et al., 2005; Mattson et al., 2002b; Musso, 2003).

Cylindrical electrodes can be installed in different configurations such as unidirectional, bidirectional, and radial-bidirectional as well as in form of radial pairs (Gill et al., 2014). Using an electrode matrix and making dynamic adjustments in a certain order can change the electric field distribution, which can also speed up the directional accumulation and separation of pollutants, promoting their degradation. Under a non-uniform electric field, a square electrode matrix of four electrode pairs was set, and the electric field distribution was adjusted every $3 \mathrm{~h}$, which promoted the degradation of phenol. The phenol removal rate reached $58 \%$ after 10 days, and the high-frequency switching of the electric field distribution effectively prevented problems of uneven migration of pollutants in non-uniform electric fields (Luo et al., 2006).

Finally, the use of pulsed power can significantly reduce power consumption and improve the removal efficiency of heavy metals. Compared with traditional electric repair, using high frequencies $(0.33-0.5 \mathrm{~Hz})$ of the pulse power supply can effectively promote the desorption of ions near the anode, enhance their migration ability, and ultimately greatly improve the removal rate of heavy metals (Ryu et al., 2010).

\subsection{Multi-technology Integration}

\subsubsection{Electro-kinetic Fenton}

Advanced oxidation processes can promote the degradation of organic pollutants, thereby increasing their removal efficiency. Electro-kinetic Fenton is an electro-kinetic process that utilizes Fenton's reagent as a flushing solution (Fernández de Dios et al., 2014; Ng et al., 2014). The Fenton process produces hydroxyl radicals $(\cdot \mathrm{OH})$ by the reaction of hydrogen peroxide and ferrous ions $\left(\mathrm{Fe}^{2+}+\mathrm{H}_{2} \mathrm{O}_{2} \rightarrow \mathrm{Fe}^{3+}+\cdot \mathrm{OH}+\mathrm{OH}^{-}\right)$, and $\cdot \mathrm{OH}$ is a strong oxidant for most organic contaminants (Ni et al., 2018). The EK Fenton process can contribute to the transport of $\mathrm{H}_{2} \mathrm{O}_{2}$ through the soil. In the presence of iron or other transition metal minerals, this process decomposes $\mathrm{H}_{2} \mathrm{O}_{2}$ and generates $\cdot \mathrm{OH}$ and other oxidizing species such as $\mathrm{O}_{2}{ }^{-} \cdot$ and $\mathrm{HO}_{2}{ }^{2}$, which are capable of oxidizing contaminants (Paixão et al., 2020). Electro-kinetic Fenton was successfully applied to treat organic-contaminated soil, and the removal rates of $\alpha-\mathrm{HCH}$ and P, P-DDT increased from $61 \%$ and $40 \%$ to $81 \%$ and $73 \%$, respectively (Ni et al., 2018).

\subsubsection{Electro-kinetic Permeable Reaction Barrier}

A permeable reaction barrier placed in a vertical flow direction can intercept contaminated water flows and remove pollutants through physical and chemical reactions. Such systems were originally used to prevent groundwater pollution (Mumford et al., 2015). Permeable reaction barriers composed of $\mathrm{Pd} / \mathrm{Fe}$ were installed in pentachlorophenol-contaminated soil, and removed $49 \%$ of soil pentachlorophenol (Li et al., 2011). Research found that EKR technology combined with 
permeable reaction barriers composed of zero-valent iron $\left(\mathrm{Fe}^{0}\right)$ can remove $80 \%$ of perchloroethylene from soil within 10 days, which was much higher than the removal rate of EKR technology alone (Kebria et al., 2016). The use of $\mathrm{Fe}^{0}$ /activated carbon as the permeable reaction barrier material in combination with EKR has also increased the removal rates of phenanthrene and trichlorophenol by 5 and 4.5 times, respectively (Sun et al., 2017).

\subsubsection{Electro-kinetic Ultrasonic Technology}

Ultrasonic technology has been used for wastewater treatment as an advanced oxidation process (Mahvi, 2009). When EKR is enhanced by ultrasonic technology, a larger current and stronger electroosmosis is generated, which greatly increases the removal rate of organic pollutants. When EKR is conducted for treating organic contaminated soil, using ultrasonic enhancement could increase the removal rate of organic pollutants by about 10\% (Pham et al., 2009). Applying ultrasonic waves to the electro-repaired soil could also increase the enrichment of $\mathrm{Cu}^{2+}$ near the cathode by up to $43 \%$, and thus improve the removal rate of heavy metals near the anode. However, the application of ultrasonic waves would cause variation of soil $\mathrm{pH}$, making the acid zone more acidic and the cathodic zone more alkaline. Although the migration of heavy metal ions to the cathode could be promoted with the ultrasonic application, it is unable to solve the problem of cathode alkalization and precipitation (Blume \& Neis, 2004).

\subsubsection{Electro-kinetic Magnetic-Assisted Treatment}

Electro-kinetic magnetic-assisted treatment is a type of technology that makes use of the effect of magnetic field on non-ferromagnetic fluid to change the properties of the pollutants in the traditional EKR process (Wu et al., 2013). The application of the magnetic field during electrolysis will increase the effective reaction area, and thus enhance the electrolysis reaction (Lin et al., 2017). Xie and Ma (2018) employed magnetic forceassisted EKR processes to remediate triclosan; the highest removal efficiency was $65 \%$ after 10 days of reclamation. Compared with the unenhanced EKR, the electro-kinetic magnetic technology promotes the electrolysis of water, enhances the electroosmosis, and promotes electro-kinetic magnetic migration of triclosan.
Electro-kinetic magnetic technology is low-cost and eco-friendly, enhancing the efficiency of pollutant removal.

\subsubsection{Electro-kinetic-enhanced Bioremediation}

Electro-kinetic-enhanced bioremediation technology uses a direct current electric field to drive the mass transfer between organic pollutants and degradation bacteria in the soil, enhancing the bioavailability of pollutants or use the current thermal effect and electrode reaction to provide appropriate temperature, $\mathrm{pH}$, and redox conditions for the biotransformation process, and finally using microorganisms to degrade organic substances. In 2010, a bench-scale test demonstrated the potential to apply electro-kinetic-enhanced bioremediation for tetrachloroethene source remediation at a site in Skuldelev, Denmark (Mao et al., 2012).

\subsubsection{Electro-kinetic Phytoremediation}

Phytoremediation is relatively cheap and eco-friendly, but traditional phytoremediation approaches pose some limitations regarding their applications at large scale. So, there is a practical need to combine it with other technologies (Sarwar et al., 2017). In electro-kinetic phytoremediation, a redistribution of soil metals between electrode compartments and changes of plant uptake was compared with the absence of an electric field. The soil $\mathrm{pH}$ changes, normally decreasing in the anode compartment (Cang et al., 2011; O'Connor et al., 2003), which may lead to the activation of soil heavy metals in the anode region (Cang et al., 2011). Another study examined the effects of electro-kinetic amendments for phytoremediation of mixed contaminated soil, where typical silty clay soil was spiked with organic contaminants (naphthalene and phenanthrene) and heavy metals (lead, cadmium, and chromium). After 61 days of treatment, a significant reduction of heavy metals and organic contaminants in soil were detected (Chirakkara et al., 2015). For better improving the EKR performance, electro-kinetic phytoremediation could also be combined with other technologies such as electro-kinetic-ethylenediaminetetraacetic acid c o m p lex ing-phytoremediation, and electro-kinetic-ethylenediamine-N,N'-disuccinic acid chelation-phytoremediation (Margarete \& Thomas, 2001). 


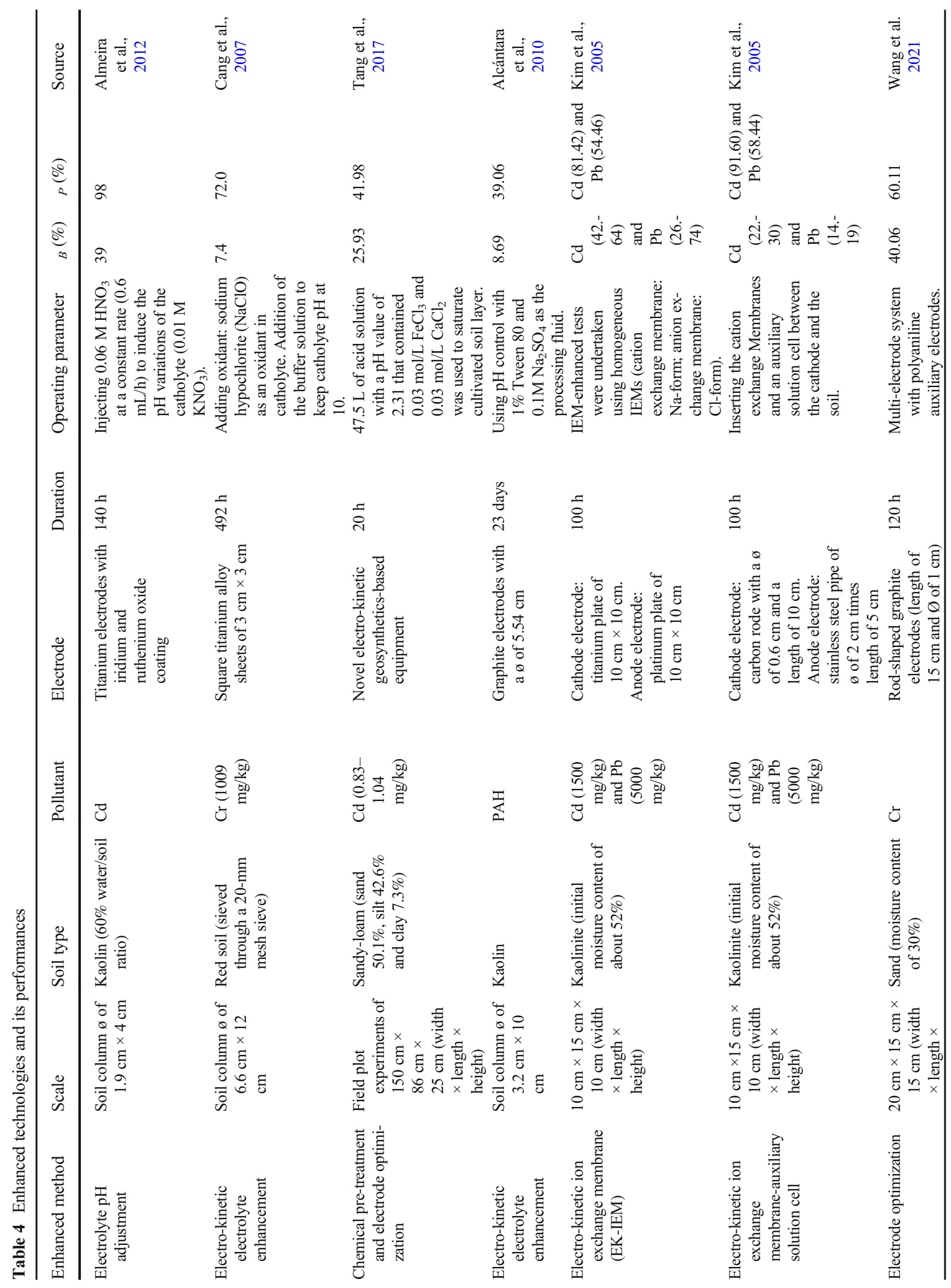




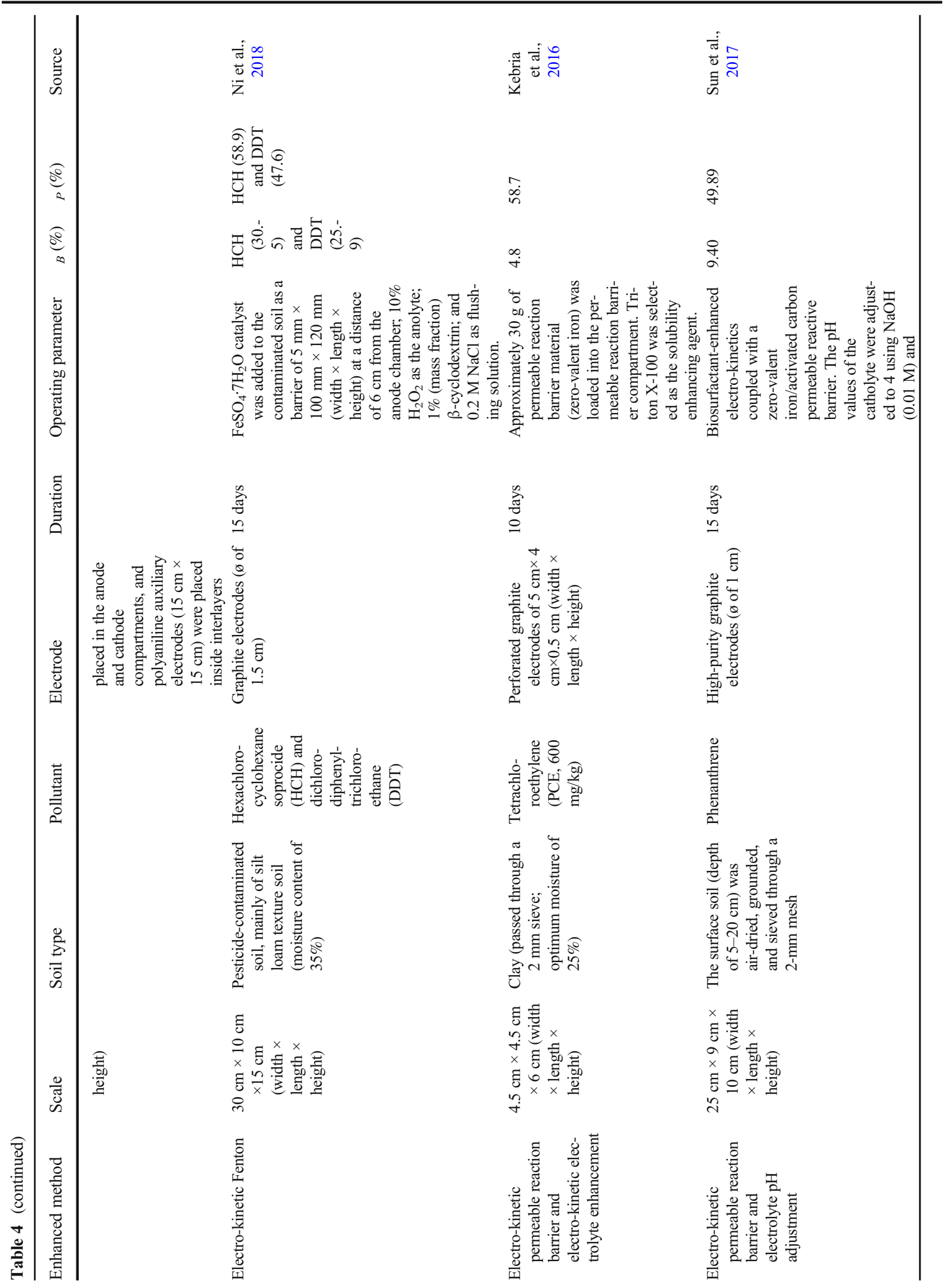




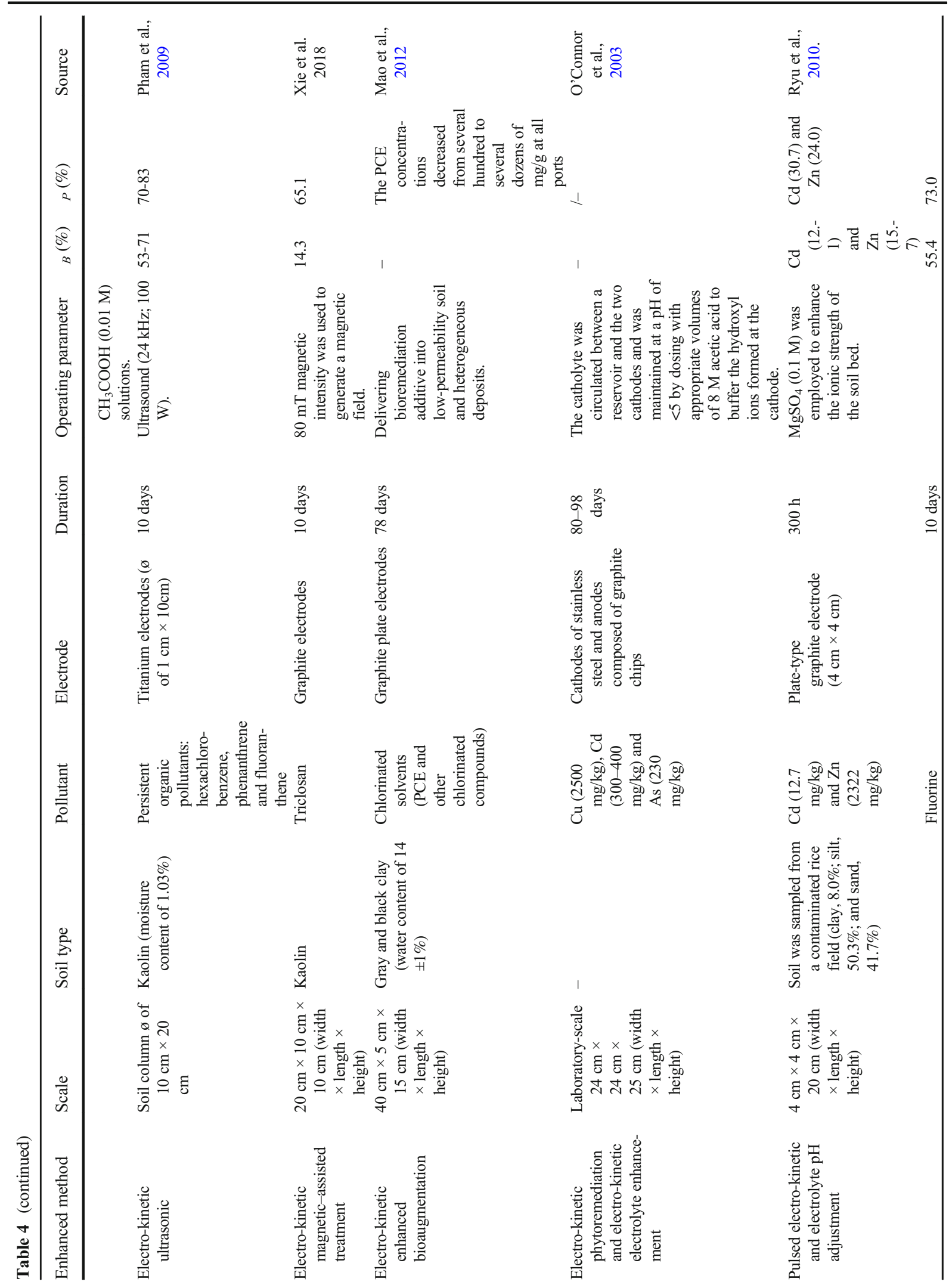




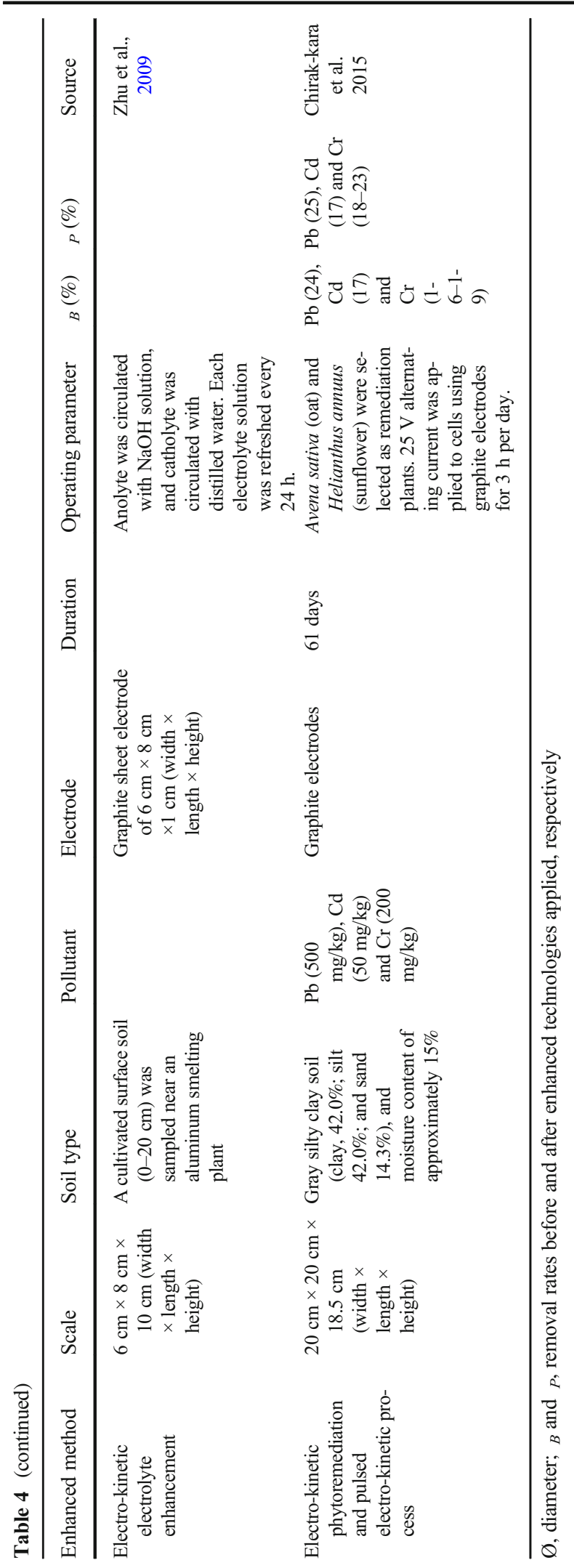




\subsection{Summary of Enhancement Technologies}

The applicable conditions of current EKR improvement technologies are variable (Table 4). For pre-treatment technology, the addition of acid or oxidant is suitable for heavy metal separation, and adding an alkali, surfactant, or co-solvent is suitable for organic pollutant removal. It is difficult to increase soil temperature and stirring in practice. In general, electrode optimization is mainly used to repair heavy metal-contaminated soil and rarely to organic pollutants. Furthermore, multi-technology integration such as electro-kinetic ion exchange membrane, electro-kinetic electrolyte enhancement, and electro-kinetic phytoremediation are mostly used for heavy metal removal, and electro-kinetic Fenton, permeable reaction barrier, and ultrasonic or magnetic-assisted repair technologies are used for treating organic pollutants.

The removal rate of pollutants has been greatly improved after using enhancement technologies. Among them, the catholyte acidification method exhibited the largest increase in the removal rate of heavy metals by up to $67 \%$. The greatest enhancement of organic pollutant removal is obtained by the electro-kinetic permeable reaction barrier, with an increased range between 40 and $50 \%$. However, most of the current EKR enhancement technologies only promoted the migration and enrichment of pollutants, and the complete separation and removal of pollutants from the soil or sediment medium were not achieved. Therefore, the development of novel EKR enhancement technology should focus on pollutant separation via pore water drainage.

\subsection{Critical Assessment of Laboratory Studies}

Field plot experiments and bench scale tests in the laboratory show that the technology is applicable for diffusely dispersed pollutants in both the non-saturated and saturated media, and it is a promising in situ remediation technology. However, most experiments were conducted with sieved artificially contaminated soil or kaolin, and experimental pollutant contents are commonly higher than those in naturally contaminated soil (Table 4). Moreover, most bench-scale experiments were conducted in the laboratory within a soil column. The number of in situ cases and the volume of treated soil are relatively small. The size of the setup can lead to different conclusions. Hence, conclusions from small-scale tests should not be directly extrapolated to full-scale applications (López-Vizcaíno et al., 2017). Laboratory test adopt artificial soil and pollutants, and the pore structure of contaminated soil as well as its content, form, and distribution of pollutants are quite different from actually polluted soil. Accordingly, the optimized parameters obtained in the laboratory cannot be directly used in the field test. The influence of uncertain factors such as influence of other contaminants, groundwater level, and soil types should be considered to bridge the gap between laboratory tests and field applications.

\section{Technical Shortages and Solutions for Electro-kinetic Remediation}

\subsection{Variation in Soil or Sediment Physicochemical Properties}

Due to EKR, storage of nutrients such as nitrogen, phosphorus, and potassium in the soil will be changed (Tang et al., 2018,2020). After EKR of fluorine-contaminated field soil, the average soil available nitrogen content increased from anode to cathode, but the average available phosphorus and potassium content decreased, but the soil available potassium content gradually increased (Zhou et al., 2015). When the EKR was applied to Cd-contaminated soil, the average content of soil available nitrogen, phosphorus, and potassium increased by $0.44,3.31$, and 1.25 times in $60 \mathrm{~h}$, while the content and morphology of organic carbon changed a little (Chen et al., 2006).

The literature review indicated that it is often easy to ignore the effects of EKR on the diversity of soil microorganisms and enzyme activities. During the practices of repairing pentachlorophenol-contaminated soil by EKR, the biomass of cultivable bacteria and fungi was decreased, and the respiration of soil microorganisms was weakened. Moreover, the use of carbon substrates significantly promoted the enrichment of pentachlorophenol around the anode (Lear et al., 2007). When EKR is conducted, a change in soil $\mathrm{pH}$ and an increase in toxicity of certain pollutants may also inhibit the reproduction of microorganisms and reduce microbial biomass and diversity (Kim et al., 2010). After EKR, the soil invertase and catalase activities increase, while soil urease and acid phosphatase activities decrease. Further correlation analysis shows that soil invertase and acid phosphatase activities are significantly related to soil 
$\mathrm{pH}$, electrical conductivity, and dissolved organic carbon content, which indicates that EKR can indirectly affect soil enzyme activities by changing soil physical and chemical properties (Cang et al., 2009).

In addition, electroosmosis also caused significant changes in soil and sediment moisture content, density, salinity, $\mathrm{pH}$, redox potential, zeta potential, and cation exchange capacity, which led to the variation in soil and sediment microcosmic structure such as pore size distribution, and resulted in the accumulation of clay particles toward the cathode and anode (Korolev \& Nesterov, 2019).

The effect of soil type and structure as well as the complexity of soil components on the efficiency of electro-kinetic treatment is less studied. The heterogeneity of soil itself leads to the migration and transformation of pollutants under the action of an electric field. Field studies are far more complex than indoor experiments. Therefore, it is important to strengthen the research in this aspect for the application of electro-kinetic remediation technology in the remediation of contaminated soil. The vast majority of contaminated sites are polluted by compounds. So, the development of electrically enhanced remediation technology for a variety of pollutants is one of the future development trends.

\subsection{Difficulties in Field Application}

Soil and sediment EKR technology mainly focused on laboratory research, and there are few applications for field practices. The effectiveness of in situ EKR depends largely on the chemical nature of the pollutants such as mobility, effectiveness, and the degree of homogenization of the sediment and soil particles (Reddy, 2010). Most of the EKR reactors are usually composed of electrodes (both anode and cathode), sample chamber, electrode chambers (both anode and cathode), and direct current power supply (Fig 1). The corresponding structure is relatively complex, which is not suitable for the field application. The following two shortages caused the limited in situ remediation practices of existing EKR technologies: the first one is the lack of an in situ EKR equipment for efficient separation and removal of pollutants. The second reason is the larger the scale of electric repair, the higher the energy consumption per unit volume of soil or sediment remediation, and the lower the removal rate of pollutants (López-Vizcaíno et al. 2016a, b; López-Vizcaíno et al., 2017).
Compared with soil, the moisture content of sediment is often high (Zhou et al., 2011), and pollutants are more easily to be migrated and subsequently be removed. So, EKR of contaminated sediment has a better application prospect (Fan et al., 2010). However, the existence of the overlying water and complicated below-water conditions hinders the application of EKR to in situ treatment of sediment, but EKR can be well used to reduce the sediment volume (Matteo et al., 2017; Tang et al., 2020) and remove harmful pollutants by the process of dewatering and electromigration. Furthermore, the behavior of the solid material is different in the field than in the laboratory, and scaling-up of the process is still challenging.

\subsection{Novel Electro-kinetic Remediation Technology for Pollutant Separation and Drainage}

Pore water is the main carrier of pollutants in soil and sediment (Booij et al., 2003). The rapid drainage of pore water can accelerate the transportation of pollutants, and separate pollutants from the soil or sediment matrix (Tang et al., 2020). At the same time, the enrichment of $\mathrm{H}^{+}$and $\mathrm{OH}^{-}$near the electrode is weakened without adding any chemical reagents. This leads to the successfull alleviation of the polarization phenomenon.

In light of the technical shortage of traditional EKR, an integrated EKR technology for systematically considering pollution separation, drainage, and treatment was proposed (Fig. 3). The technical mechanisms and advantages of this novel technology are indicated below.

The novel EKG-based equipment exhibits obvious technical potential for field application. First, pollutants can be directly and completely isolated from the soil matrix through the efficient drainage of soil water. Second, rapid and excellent dewatering properties avoid the abundant accumulation of $\mathrm{H}^{+}$and $\mathrm{OH}^{-}$near the electrodes and thus efficiently mitigate the anode acidic corrosion and cathode alkalization. Third, the equipment overcomes the shortcomings of having no facility for transporting the collected pore water to the cathode, installation difficulties, and having to maintain a large array of electrodes in the field for conducting EKG dewatering practices.

The EKG equipment is using an adsorption column to remove soluble pollutants such as $\mathrm{NH}_{4}{ }^{+}$in the pore water. After completion of adsorption, the pore water is discharged into the electrolytic cell for electrolysis. The organic matter in the waste liquid is degraded by Fenton technology. The residual pollutants are subsequently filtered through the permeable reaction barrier and the 


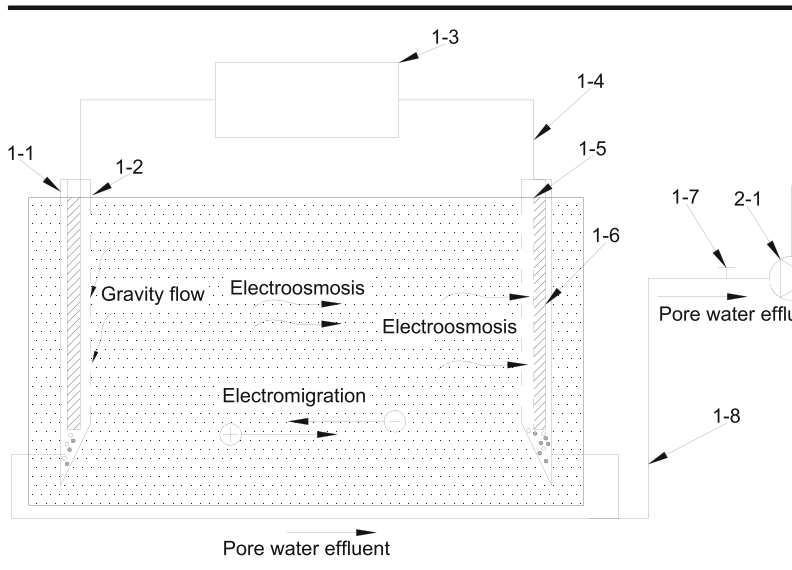

Pore water effluent

Fig. 3 Integrated electro-kinetic remediation technology based on pollutant separation, discharge and treatment. 1-1, pore water collector; 1-2, filter screen; 1-3, power supply; 1-4, waterproof wire; 1-5, cation exchange membrane; 1-6, electro-kinetic

chitosan flocculent. Finally, the $\mathrm{pH}$ is adjusted before pore water discharge. Moreover, the valuable elements including nutrients can be recycled from the effluent during these processes.

Theoretically, phosphate will be enriched in the anode electrolyte, and the ammonium ion will be in the cathode. By adding magnesium oxide or lime to the anode electrolyte, neutralizing the $\mathrm{pH}$ of the anode electrolyte and mixing the cathode electrolyte, nitrogen, and phosphorus can be recovered in the form of magnesium ammonium phosphate (struvite) or hydroxyapatite through precipitation reaction as shown in Eqs. (4) and (5) according to the literature (Dai et al., 2017; Li et al., 2019).

$$
\begin{aligned}
& \mathrm{Mg}^{2+}+\mathrm{NH}_{4}{ }^{+}+\mathrm{HPO}_{4}{ }^{2-}+\mathrm{OH}^{-} \rightarrow \mathrm{MgNH}_{4} \mathrm{PO}_{4} \downarrow \\
& \quad+\mathrm{H}_{2} \mathrm{O} \\
& 5 \mathrm{Ca}^{2+}+\mathrm{PO}_{4}{ }^{3-}+\mathrm{OH}^{-} \rightarrow \mathrm{Ca}_{5}\left(\mathrm{PO}_{4}\right)_{3} \mathrm{OH} \downarrow
\end{aligned}
$$

\section{Conclusions and Further Research Needs}

Electroosmosis and electromigration dominates most of the pollutant removal via EKR. The current EKR models mainly focus on the process of ion transfer. As the main carrier of pollutants in soil and sediment medium, pore water migration and distribution should be studied to describe and reveal the mechanisms of EKR.

Electrolyte $\mathrm{pH}$ adjustment, electrode optimization, and multi-technology combination are mainly used to improve EKR performance. Commonly co-existing

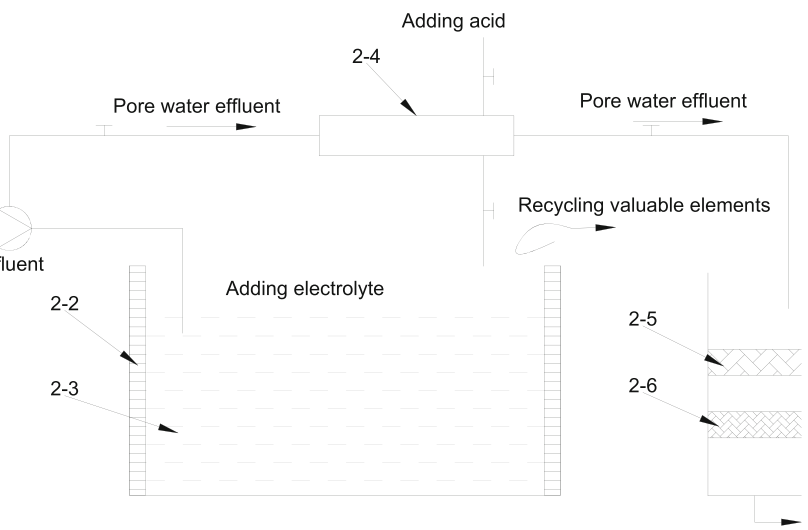

Discharge after $\mathrm{pH}$ adjustment

geosynthetics electrode; 1-7, control valve; 1-8, catheter; 2-1, pump; 2-2, electrode; $2-3$, electrolyze; $2-4$, humic acid resin adsorption column; 2-5, permeable reactive barrier; 2-6, chitosan (linear polysaccharide) flocculent

pollutants in soil and sediment behave differently in the electric field. Low soluble heavy metals are prone to be precipitated in the alkaline cathode zone, and organic pollutants are easy to adsorb to soil and sediment particles. These processes may hinder EKR performance.

The key to improve the efficiency of EKR is transferring pollutants from the solid to the liquid phase. To date, most EKR enhancement technologies only promote the migration and enrichment of pollutants near the electrode zone, but do not actually achieve the separation and removal of pollutants. Therefore, it is necessary to develop a novel EKR technology based on pore water drainage and associated pollutant separation.

The majority of research studies were conducted in the laboratory and focused on the EKR performance and mechanisms. It follows that limited studies address the practical issues due to shortage of in situ EKR equipment. Developing the mechanism model both considering the pore water and pollutant migration, distribution and removal is also recommended to reveal the actual EKR processes and optimize the technology parameters to guide the field applications.

Acknowledgements This study was supported by the National Natural Science Foundation of China (51979006\&41907401), and the Outstanding Young Talents of National High-Level Personnel of the Special Support Program (CKSD2019542/SH). The work by Miklas Scholz was funded by WATERAGRI project (European Union Horizon 2020 research and innovation program under Grant Agreement Number 858735). 
Code Availability Not applicable. No custom code required.

Author Contribution All authors read and approved the final manuscript.

Funding Open access funding provided by Lund University.

Data Availability The authors confirm that the data supporting the findings of this study are available within the article.

\section{Declarations}

Conflict of Interest The authors declare that they have no conflict of interest.

Ethics Approval Not applicable. No animal or human participants.

Consent to Participate Not applicable. No animal or client participants.

Consent for Publication Not applicable. No individual person's data in any form.

Open Access This article is licensed under a Creative Commons Attribution 4.0 International License, which permits use, sharing, adaptation, distribution and reproduction in any medium or format, as long as you give appropriate credit to the original author(s) and the source, provide a link to the Creative Commons licence, and indicate if changes were made. The images or other third party material in this article are included in the article's Creative Commons licence, unless indicated otherwise in a credit line to the material. If material is not included in the article's Creative Commons licence and your intended use is not permitted by statutory regulation or exceeds the permitted use, you will need to obtain permission directly from the copyright holder. To view a copy of this licence, visit http://creativecommons.org/licenses/by/4.0/.

\section{References}

Acar, Y. B., \& Alshawabkeh, A. N. (1993). Principles of electrokinetic remediation. Environmental Science \& Technology, 27(13), 2638-2647.

Acar, Y. B., Li, H., \& Gale, R. J. (1992). Phenol removal from kaolinite by electrokinetics. Journal of Geotechnical Engineering, 118(11), 1837-1852.

Acar, Y. B., Alshawabkeh, A. N., \& Gale, R. J. (1993). Fundamentals of extracting species from soils by electrokinetics. Waste Management, 13(2), 141-151.

Alcántara, M. T., Gómez, J., Pazos, M., \& Sanromán, M. A. (2010). Electrokinetic remediation of PAH mixtures from kaolin. Journal of Hazardous Materials, 179(1-3), 11561160 .
Al-Hamdan, A. Z., \& Reddy, K. R. (2008). Transient behaviour of heavy metals in soils during electrokinetic remediation. Chemosphere, 71(5), 860-871.

Almeira, J., Peng, C. S., \& Abou-Shady, A. (2012). Simultaneous removal of cadmium from kaolin and catholyte during soil electrokinetic remediation. Desalination, 300, 1-11.

Altin, A., \& Degirmenci, M. (2005). Lead (II) removal from natural soils by enhanced electrokinetic remediation. the. Science of the Total Environment, 337(1-3), 1-10.

Andreottola, G., Bonomo, L., Gioannis, G. D., Ferrarese, E., Muntoni, A., Polettini, A., Pomi, R., \& Saponaro, S. (2010). Lab-scale feasibility tests for sediment treatment using different physico-chemical techniques. Journal of Soils and Sediments, 10(1), 142-150.

Annamalai, S., Santhanam, M., Sundaram, M., \& Curras, M. P. (2014). Electrokinetic remediation of inorganic and organic pollutants in textile effluent contaminated agricultural soil. Chemosphere, 117(1), 673-678.

Baraud, F., Tellier, S., \& Astruc, M. (1999). Temperature effect on ionic transport during soil electrokinetic treatment at constant pH. Journal of Hazardous Materials, 64(3), 263-281.

Blume, T., \& Neis, U. (2004). Improved wastewater disinfection by ultrasonic pre-treatment. Ultrasonics Sonochemistry, 11 (5), 333-336.

Booij, K., Hoedemaker, J. R., \& Bakker, J. F. (2003). Dissolved PCBs, PAHs, and HCB in pore waters and overlying waters of contaminated harbor sediments. Environmental Science \& Technology, 37(18), 4213-4220.

Bruell, C. J., Segall, B. A., \& Walsh, M. T. (1992). Electroosomotic removal of gasoline hydrocarbons and TCE from clay. Journal of Environmental Engineering, 118(1), 68-83.

Cabrera-Guzmán, D., Swartzbaugh, J. T., \& Weisman, A. W. (1990). The use of electrokinetics for hazardous waste site remediation. Journal of the Air \& Waste Management Association, 40(12), 1670-1676.

Cameselle, C., \& Reddy, K. R. (2013). Effects of periodic electric potential and electrolyte recirculation on electrochemical remediation of contaminant mixtures in clayey soils. Water Air Soil Pollut., 224, 1636.

Cang, L., Zhou, D. M., Alshawabkeh, A. N., \& Chen, H. F. (2007). Effects of sodium hypochlorite and high $\mathrm{pH}$ buffer solution in electrokinetic soil treatment on soil chromium removal and the functional diversity of soil microbial community. Journal of Hazardous Materials, 142(1-2), 111-117.

Cang, L., Zhou, D. M., Wang, Q. Y., \& Wu, D. Y. (2009). Effects of electrokinetic treatment of a heavy metal contaminated soil on soil enzyme activities. Journal of Hazardous Materials, 172(2-3), 1602-1607.

Cang, L., Wang, Q., Zhou, D., \& Xu, H. (2011). Effects of electrokinetic-assisted phytoremediation of a multiple-metal contaminated soil on soil metal bioavailability and uptake by Indian mustard. Separation \& Purification Technology, 79, 246-253.

Casagrande, L. (1948). Electroosmosis in soils. Geotechnique, 1, 159-177.

Chen, X., Shen, Z., Lei, Y., Zhang, S., Ju, B., \& Wang, W. (2006). Effects of electrokinetics on bioavailability of soil nutrients. Soil Science, 171(8), 638-647.

Chirakkara, R. A., Reddy, K. R., \& Cameselle, C. (2015). Electrokinetic amendment in phytoremediation of mixed contaminated soil. Electrochimica Acta, 181, 179-191. 
Chung, H. I., \& Kamon, M. (2005). Ultrasonically enhanced electrokinetic remediation for removal of $\mathrm{Pb}$ and phenanthrene in contaminated soils. Engineering Geology, 77(34), 233-242.

Cox, C. D., Shoesmith, M. A., \& Ghosh, M. M. (1996). Electrokinetic remediation of mercury-contaminated soils using iodine/iodide lixiviant. Environmental Science \& Technology, 30(6), 1933-1938.

Dai, H., Lu, X., Peng, Y., \& Zhsssu, H. (2017). Effects of supersaturation control strategies on hydroxyapatite (HAP) crystallization for phosphorus recovery from wastewater. Environmental Science and Pollution Research, 24, 5791-5799.

Davis, R. J., Kim, Y., \& Logan, B. E. (2013). Increasing desalination by mitigating anolyte $\mathrm{pH}$ imbalance using catholyte effluent addition in a multi-anode bench scale microbial desalination cell. ACS Sustainable Chemistry \& Engineering, 1(9), 1200-1206.

Fan, J. T., Miller, D. R., Zhang, L. W., \& Sun, J. H. (2010). Effects of bark beetle pheromones on the attraction of Monochamus alternatus to pine volatiles. Insect Science, 17(6), 553-556.

Fernández de Dios, M. Á., Iglesias, O., Pazos, M., \& Sanromán, M. Á. (2014). Application of electro-Fenton technology to remediation of polluted effluents by self-sustaining process. The Scientific World Journal, 801870. https://doi. org/10.1155/2014/801870.

Ferro, S., Rosestolato, D., \& Bagatin, R. (2014). Electrokinetic remediation of soils polluted by heavy metals (mercury in particular). The Chemical Engineering Journal, 264, 16-23.

Forstner, U. (2004). Sediment dynamics and pollutant mobility in rivers: an interdisciplinary approach. Lakes \& Reservoirs Research \& Management, 9(1), 25-40.

Fu, R., Wen, D., Xia, X., Zhang, W., \& Gu, Y. (2017). Electrokinetic remediation of chromium $(\mathrm{Cr})$-contaminated soil with citric acid (CA) and polyaspartic acid (PASP) as electrolytes. Chemical Engineering Journal, 316, 601-608.

Gill, R. T., Harbottle, M. J., Smith, J. W. N., \& Thornton, S. F. (2014). Electrokinetic-enhanced bioremediation of organic contaminants: a review of processes and environmental applications. Chemosphere, 107, 31-42.

Isosaari, P., Piskonen, R., Ojala, P., Voipio, S., Eilola, K., Lehmus, E., \& Itävaara, M. (2007). Integration of electrokinetics and chemical oxidation for the remediation of creosote-contaminated clay. Journal of Hazardous Materials, 144(1-2), 538-548.

Jacobs, R. A., \& Probstein, R. F. (1996). Two-dimensional modelling of electroremediation. AIChE Journal, 42(6), 1685-1696.

Kebria, D. Y., Taghizadeh, M., Camacho, J. V., \& Latifi, N. (2016). Remediation of PCE contaminated clay soil by coupling electrokinetics with zero-valent iron permeable reactive barrier. Environmental Earth Sciences, 75(8), 699.

Kim, W. S., Kim, S. O., \& Kim, K. W. (2005). Enhanced electrokinetic extraction of heavy metals from soils assisted by ion exchange membranes. Journal of Hazardous Materials, 118 (1-3), 93-102.

Kim, S. H., Han, H. Y., Lee, Y. J., Kim, C. W., \& Yang, J. W. (2010). Effect of electrokinetic remediation on indigenous microbial activity and community within diesel contaminated soil. the. Science of the Total Environment, 408(16), 3162-3167.

Kim, L. Y., Choi, J. H., \& Lee, Y. J. (2012). A Study on salt removal in controlled cultivation soil using electrokinetic technology. Korean Journal of Soil Science \& Fertilizer, 45 (6), 1230-1236.
Korolev, V. A., \& Nesterov, D. S. (2019). Influence of electroosmosis on physicochemical parameters and microstructure of clay soils. Journal of Environmental Science \& Health, Part A, 54(6), 1-12.

Krause, T. R., \& Tarman, B. (1993). Preliminary results from the investigation of thermal effects in electrokinetics soil remediation. Farmakologiia i toksikologiia, 31(1), 32-34.

Lear, G., Harbottle, M. J., Sills, G., Knowles, C. J., Semple, K. T., \& Thompson, I. P. (2007). Impact of electrokinetic remediation on microbial communities within PCP contaminated soil. Environmental Pollution, 146(1), 139-146.

Lee, Y. J., Choi, J. H., Lee, H. G., Ha, T. H., \& Bae, J. H. (2011). Pilot-scale study on in situ electrokinetic removal of nitrate from greenhouse soil. Separation and Purification Technology, 79(2), 254-263.

Li, A., Cheung, K. A., \& Reddy, K. R. (2000). Cosolventenhanced electrokinetic remediation of soils contaminated with phenanthrene. Journal of Environmental Engineering, 126(6), 527-533.

Li, Z., Yuan, S., Wan, J., Long, H., \& Tong, M. (2011). A combination of electrokinetics and Pd/Fe PRB for the remediation of pentachlorophenol-contaminated soil. Journal of Contaminant Hydrology, 124(1-4), 99-107.

Li, H., Muhammad, F., Yan, Y., Zhang, M., Jiao, B., Yu, L., \& Li, D. (2018). Electrokinetic remediation of heavy metals from municipal solid waste incineration fly ash pretreated by nitric acid. Royal Society Open Science, 5(8), 180372.

Li, B., Huang, H., Boiarkina, I., Yu, W., Huang, Y., Wang, G., \& Young, B. (2019). Phosphorus recovery through struvite crystallisation: recent developments in the understanding of operational factors. Journal of Environmental Management, $248,109254$.

Lima, A. T., Ottosen, L. M., Heister, K., \& Loch, J. P. G. (2012). Assessing PAH removal from clayey soil by means of electro-osmosis and electrodialysis. The Science of The Total Environment, 435-436 1-6.

Lin, M. Y., Hourng, L. W., \& Wu, C. H. (2017). The effectiveness of a magnetic field in increasing hydrogen production by water electrolysis. Energy Sources, 39(2), 140-147.

Lindgren, E. R., Mattson, E. D., Kozak, M. W. (1994). Electrokinetic remediation of unsaturated soils. Emerging Technologies in Hazardous Waste Management IV, chapter 3 (pp. 33-50). American Chemical Society Symposium Series, Vol. 554, Washington, DC: American Chemical Society.

López-Vizcaíno, R., Navarro, V., Alonso, J., Yustres, A., Cañizares, P., Rodrigo, M., \& Sáez, C. (2016a). Geotechnical behaviour of low-permeability soils in surfactant-enhanced electrokinetic remediation. Environmental Science and Health, 51(1), 44-51.

López-Vizcaíno, R., Navarro, V., León, M. J., Risco, C., Rodrigo, M. A., Sáez, C., \& Cañizares, P. (2016b). Scale-up on electrokinetic remediation: engineering and technological parameters. Journal of Hazardous Materials, 315, 135-143.

López-Vizcaíno, R., Risco, C., Isidro, J., Rodrigo, S., Saez, C., Cañizares, P., Navarro, V., \& Rodrigo, M. A. (2017). Scaleup of the electrokinetic fence technology for the removal of pesticides. Part II: Does size matter for removal of herbicides. Chemosphere, 166, 549-555.

López-Vizcaíno, R., Yustres, A., Asensio, L., Saez, C., Cañizares, P., Rodrigo, M. A., \& Navarro, V. (2018). Enhanced 
electrokinetic remediation of polluted soils by anolyte $\mathrm{pH}$ conditioning. Chemosphere, 199, 477-485.

Lucas, M., Vahid, A., \& Jay, M. (2019). Electro-osmosis treatment techniques and their effect on dewatering of soils, sediments, and sludge: a review. Soils and Foundations, 59(2), 407-418.

Luo, Q., Zhang, X., Wang, H., \& Qian, Y. (2005). Mobilization of phenol and dichlorophenol in unsaturated soils by nonuniform electrokinetics. Chemosphere, 59(9), 1289-1298.

Luo, Q., Wang, H., Zhang, X., Fan, X., \& Qian, Y. (2006). In situ bio electrokinetic remediation of phenol-contaminated soil by use of an electrode matrix and a rotational operation mode. Chemosphere, 64(3), 415-422.

Mahvi, A. H. (2009). Application of ultrasonic technology for water and wastewater treatment. Iranian Journal of Public Health, 38(2), 1-17.

Manokararajah, K., \& Ranjan, R. S. (2005). Electrokinetic denitrification of nitrates in a nitrate contaminated silty loam soil. Applied Engineering in Agriculture, 21(3), 541-549.

Mao, T., \& Pan, T. (2015). A multiphysics model for evaluating electrokinetic remediation of nuclear waste-contaminated soils. Water Air Soil Pollut, 226, 77.

Mao, X., Wang, J., Ciblak, A., Cox, E. E., Riis, C., Terkelsen, M., Gent, D. B., \& Alshawabkeh, A. N. (2012). Electrokineticenhanced bioaugmentation for remediation of chlorinated solvents contaminated clay. Journal of Hazardous Materials, 213-214, 311-317.

Margarete, B. W., \& Thomas, E. (2001). Environmental fate and microbial degradation of aminopolycarboxylic acids. FEMS Microbiology Reviews, 25(1), 69-106.

Matteo, M., Alessio, C., \& Renato, I. (2017). Model-based optimization of field-scale electrokinetic treatment of dredged sediments. Chemical Engineering Journal, 328, 87-97.

Mattson, E. D., Bowman, R. S., \& Lindgren, E. R. (2002a). Electrokinetic ion transport through unsaturated soil: 1 . Theory, model development, and testing. Journal of Contaminant Hydrology, 54(1-2), 99-120.

Mattson, E. D., Bowman, R. S., \& Lindgren, E. R. (2002b). Electrokinetic ion transport through unsaturated soil: 2 . Application to a heterogeneous field site. Journal of Contaminant Hydrology, 54(1-2), 121-140.

Maturi, K., \& Reddy, K. R. (2008). Cosolvent-enhanced desorption and transport of heavy metals and organic contaminants in soils during electrokinetic remediation. Water, Air \& Soil Pollution, 189(1-4), 199-211.

Méndez, E., Pérez, M., Romero, O., Beltrán, E. D., Castro, S., Corona, J. L., Corona, A., Cuevas, M. C., \& Bustos, E. (2012). Effects of electrode material on the efficiency of hydrocarbon removal by an electrokinetic remediation process. Electrochimica Acta, 86, 148-156.

Meng, F., Nie, L., Xue, H., \& Zhang, D. (2018). Potassium permanganate oxidation-electrokinetic advanced remediation for soils contaminated with trivalent chromium. Journal of Agro-Environment Science, 37(6), 1125-1131 (in Mandarin)

Micic, S., Shang, J. Q., Lo, K. Y., Lee, Y. N., \& Lee, S. W. (2001). Electrokinetic strengthening of a marine sediment using intermittent current. Canadian Geotechnical Journal, 38(2), 287-302.

Mumford, K. A., Powell, S. M., Rayner, J. L., Hince, G., \& Stevens, G. W. (2015). Evaluation of a permeable reactive barrier to capture and degrade hydrocarbon contaminants. Environmental Science \& Pollution Research, 22(16), 12298-12308.
Musso, G. (2003). Transport phenomena in electrokinetic soil remediation. Mathematical \& Computer Modelling, 37(56), 589-594.

Ng, Y. S., Sen Gupta, B., \& Hashim, M. A. (2014). Stability and performance enhancements of electrokinetic-Fenton soil remediation. Reviews in Environmental Science and Bio/ Technology, 13, 251-263.

Ni, M., Tian, S., Huang, Q., \& Yang, Y. (2018). ElectrokineticFenton remediation of organochlorine pesticides from historically polluted soil. Environmental Science \& Pollution Research, 25(12), 12159-12168.

O'Connor, C. S., Lepp, N. W., Edwards, R., \& Sunderland, G. (2003). The combined use of electrokinetic remediation and phytoremediation to decontaminate metal-polluted soils: a laboratory-scale feasibility study. Environmental Monitoring \& Assessment, 84, 141-158.

Paixão, I. C., López-Vizcaíno, R., Solano, A. M. S., MartinezHuitle, C. A., Navarro, V., Rodrigo, M. A., \& Dos Santos, E. (2020). Electrokinetic-Fenton for the remediation low hydraulic conductivity soil contaminated with petroleum. Chemosphere., 248, 126029.

Pazos, M., Sanroman, M. A., \& Cameselle, C. (2006). Improvement in electrokinetic remediation of heavy metal spiked kaolin with the polarity exchange technique. Chemosphere, 62(5), 817-822.

Pedersen, K. B., Lejon, T., Jensen, P. E., \& Ottosen, L. M. (2016). Degradation of oil products in a soil from a Russian Barents hotspot during electrodialytic remediation. SpringerPlus, 5(1), 168.

Pham, T. D., Shrestha, R. A., Virkutyte, J., \& Sillanp, M. (2009). Combined ultrasonication and electrokinetic remediation for persistent organic removal from contaminated kaolin. Electrochimica Acta, 54(5), 1403-1407.

Probstein, R. F., \& Hicks, R. E. (1993). Removal of contaminants from soils by electric fields. Science, 260(5107), 498-503.

Reddy, K. R. (2010). Technical challenges to in-situ remediation of polluted sites. Geotechnical and Geological Engineering, 28(3), 211-221.

Reddy, K. R., \& Saichek, R. E. (2003). Effect of soil type on electrokinetic removal of phenanthrene using surfactants and cosolvents. Journal of Environmental Engineering, 129(4), 336-346.

Ricart, M. T., Pazos, M., Gouveia, S., Cameselle, C., \& Sanroman, M. A. (2008). Removal of organic pollutants and heavy metals in soils by electrokinetic remediation. Journal of Environmental Science and Health, 43(8), 871-875.

Rodríguez-Maroto, J. M., \& Vereda-Alonso, C. (2009). Electrokinetic modeling of heavy metals. Electrochemical Remediation Technologies for Polluted Soils, Sediments and Groundwater, 537-562. https://doi.org/10.1002 /9780470523650.ch25.

Rojo, A., Hansen, H. K., \& Cubillos, M. (2012). Electrokinetic remediation using pulsed sinusoidal electric field. Electrochimica Acta, 86, 124-129.

Ryu, B. G., Yang, J. S., Kim, D. H., \& Baek, K. (2010). Pulsed electrokinetic removal of $\mathrm{Cd}$ and $\mathrm{Zn}$ from fine-grained soil. Journal of Applied Electrochemistry, 40(6), 1039-1047.

Sarwar, N., Imran, M., Shaheen, M. R., Ishaque, W., Kamran, M. A., Matloob, A., Rehim, A., \& Hussain, S. (2017). Phytoremediation strategies for soils contaminated with heavy metals: modifications and future perspectives. Chemosphere, 171, 710-721. 
Shen, Z., Chen, X., Jia, J., Qu, L., \& Wang, W. (2007). Comparison of electrokinetic soil remediation methods using one fixed anode and approaching anodes. Environmental Pollution, 150(2), 193-199.

Sprocati, R., \& Rolle, M. (2020). Charge interactions, reaction kinetics and dimensionality effects on electrokinetic remediation: a model-based analysis. Journal of Contaminant Hydrology, 229, 103567.

Sprocati, R., Masi, M., Muniruzzaman, M., \& Rolle, M. (2019). Modeling electrokinetic transport and biogeochemical reactions in porous media: a multidimensional Nernst-PlanckPoisson approach with PHREEQC coupling. Advances in Water Resources, 127, 134-147.

Sun, Y., Gao, K., Zhang, Y., \& Zou, H. (2017). Remediation of persistent organic pollutant-contaminated soil using biosurfactant-enhanced electrokinetics coupled with a zerovalent iron/activated carbon permeable reactive barrier. Environmental Science \& Pollution Research, 24(36), 28142-28151.

Sun, Z., Wu, B., Guo, P., Wang, S., \& Guo, S. (2019). Enhanced electrokinetic remediation and simulation of cadmiumcontaminated soil by superimposed electric field. Chemosphere, 233, 17-24.

Tang, X., Li, Q., Wang, Z., Hu, Y., Hu, Y., \& Li, R. (2017). In situ electrokinetic isolation of cadmium from paddy soil through pore water drainage: effects of voltage gradient and soil moisture. Chemical Engineering Journal, 337, 210-219.

Tang, X., Li, Q., Wang, Z., Hu, Y., Hu, Y., \& Scholz, M. (2018). Improved isolation of cadmium from paddy soil by novel technology based on pore water drainage with graphitecontained electro-kinetic geosynthetics. Environmental Science \& Pollution Research, 25(14), 14244-14253.

Tang, X., Li, R., Han, D., \& Wu, X. (2020). Impacts of electrokinetic isolation of phosphorus through pore water drainage on sediment phosphorus storage dynamics. Environmental Pollution, 266(Part 2), 115210.

Tang, J., Qiu, Z., Tang, H., Wang, H., Sima, W., Liang, C., Liao, Y., Li, Z., Wan, S., \& Dong, J. (2021). Coupled with EDDS and approaching anode technique enhanced electrokinetic remediation removal heavy metal from sludge. Environmental Pollution, 272, 115975.

Vocciante, M., Bagatin, R., \& Ferro, S. (2017). Enhancements in electrokinetic remediation technology: focus on water management and wastewater recovery. Chemical Engineering Journal, 309, 708-716.
Wang, Y., Li, A., \& Cui, H. (2021). Remediation of heavy metalcontaminated soils by electrokinetic technology: mechanisms and applicability. Chemosphere, 265, 129071.

Wu, C., Yao, Y., \& Xie, Q. (2013). Synergy remediation of PBDEs contaminated soil by electric - magnetic method. Advanced Materials Research, 726, 2338-2341.

Wu, J., Wei, B., Lv, Z., \& Fu, Y. (2021). To improve the performance of focusing phenomenon related to energy consumption and removal efficiency in electrokinetic remediation of Cr-contaminated soil. Separation and Purification Technology, 118882.

Xiao, J., Zhou, S., Chu, L., \& Liu, Y. (2020). Electrokinetic remediation of uranium(VI)-contaminated red soil using composite electrolyte of citric acid and ferric chloride. Environmental Science and Pollution Research, 27, 44784488.

Xie, Q., \& Ma, X. (2018). Magnetic force-assisted electrokinetic remediation of triclosan-contaminated soil. Journal of Jiangsu University (Natural Science), 39(1), 92-95 (in Mandarin).

Xue, Z., Tang, X., \& Yang, Q. (2017). Influence of voltage and temperature on electro-osmosis experiments applied on marine clay. Applied Clay Science, 141, 13-22.

Zhou, D. M., Alshawabkeh, A. N., Deng, C. F., Cang, L., \& Si, Y. B. (2004). Electrokinetic removal of chromium and copper from contaminated soils by lactic acid enhancement in the catholyte. Journal of Environmental Sciences, 16(4), 529532.

Zhou, A. X., Chen, N., Lu, J. Y., Fang, F., \& Guo, J. S. (2011). Analysis and evaluation of sediment pollutant of secondary rivers of the three gorges reservoir. Procedia Environmental Sciences, 10, 2147-2152.

Zhou, M., Zhu, S., Liu, Y., \& Wang, H. (2014). Electrokinetic remediation of fluorine-contaminated soil using approaching cathodes. CLEAN - Soil, Air, Water, 42(12), 1771-1775.

Zhou, M., Wang, H., Zhu, S., Liu, Y., \& Xu, J. (2015). Electrokinetic remediation of fluorine-contaminated soil and its impact on soil fertility. Environmental Science \& Pollution Research, 22(21), 16907-16913.

Zhu, S., Zhang, J., \& Dong, T. (2009). Removal of fluorine from contaminated field soil by anolyte enhanced electrokinetic remediation. Environmental Earth Sciences, 59, 379-384.

Publisher's Note Springer Nature remains neutral with regard to jurisdictional claims in published maps and institutional affiliations. 